$$
\begin{aligned}
& \text { جامعـة المنصــورة } \\
& \text { كليـــة التربية }
\end{aligned}
$$

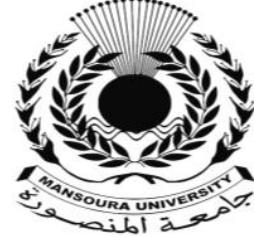

\title{
التأخر الدراسي وعلاقته بتمقيق الذات على \\ عينة هن طالبات المرحلة الثانوية في مدينة \\ أبها بمنطقة عسير
}

$$
\begin{aligned}
& \text { إعداد } \\
& \text { شيمه مهدي صالح العامر الوادعي } \\
& \text { إثــــــر اف الات } \\
& \text { د.عبد الوهاب مشرب الإنديجاني } \\
& \text { أستاذ الإرشاد النفسي المشارك الإكان } \\
& \text { كلية التربية - جامعة الباحة }
\end{aligned}
$$

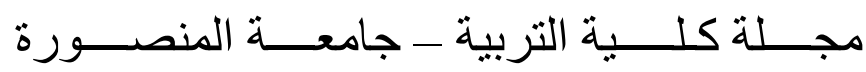

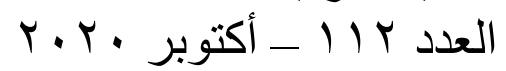


التأخر الدر اسي و علاقته بتحقيق الذات على عينة من طالبات المرحلة الثانوية

\author{
في مدينة أبها بمنطقة عسير
}

\title{
شيمه مهذي صالح العامر الوادعي
}

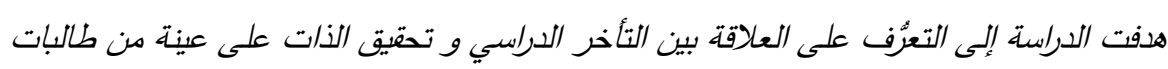

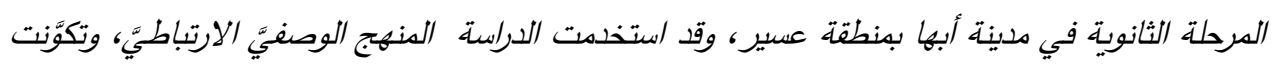

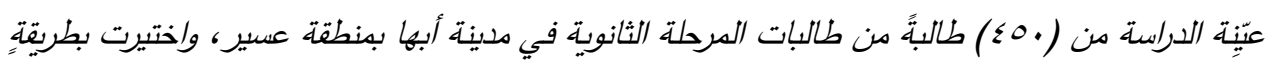

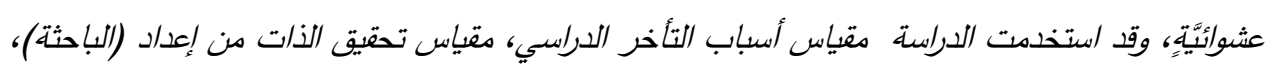

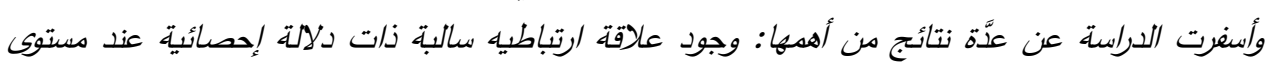

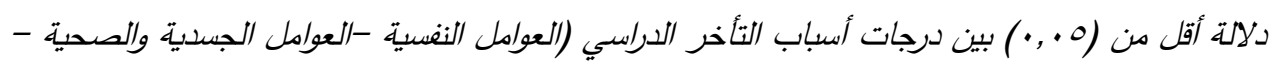

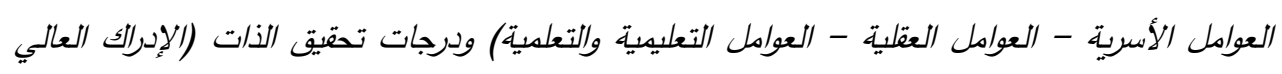

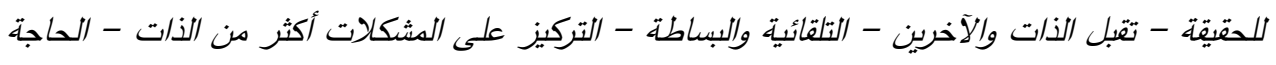

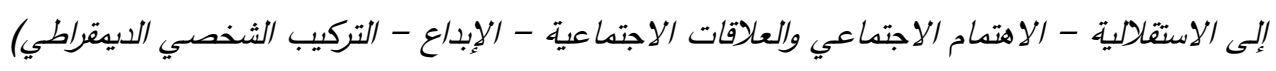

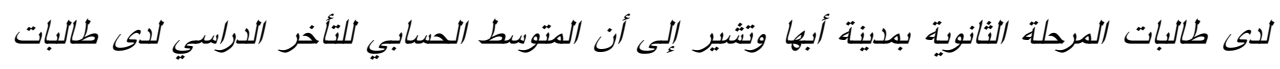

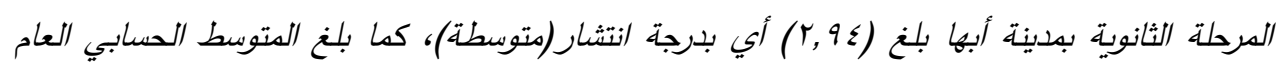

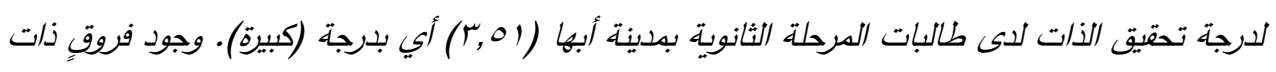

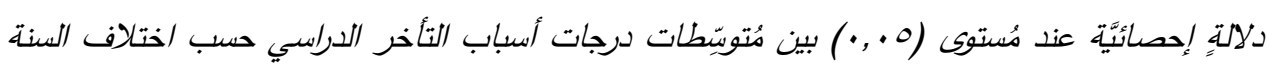

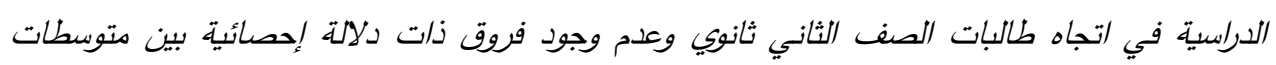

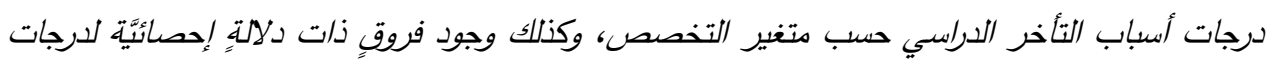

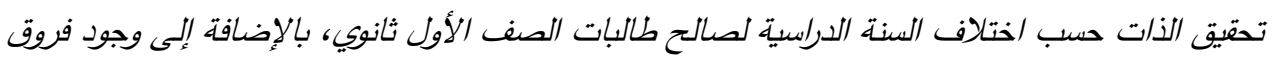

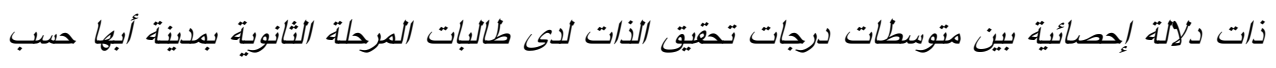

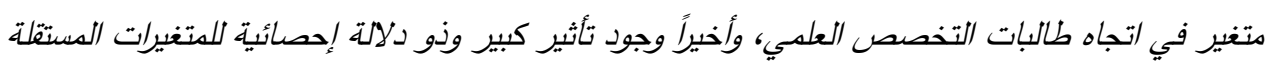
(أسباب التأخر الدراسي) على الكتغير التابع (تحقيق الذات). 
Abstrac

The study aimed to Investigate the relationship between Low academic achievement and its relation to self-realization on a sample of students from secondary school in Abha city, Asir region, the researcher used the descriptive correlative, and the study sample consisted of (450) students from the students of the secondary school in Abha city, Asir region, and were selected in a random way, the researcher used Instruments of the study of the scale the reasons for the delay study, a measure of the self-realization of Was developed by the researcher (the researcher), and the study resulted in several findings including: the existence of a committed relationship abuse and negative statistically significant at level of significance less than (0.05) Among the score of reasons for academic delays (factors psychological factors physical health - Family factors - mental factors - factors educational) and self-realization (realization of higher truth - to accept self and others automatic and simplicity - to focus on problems more than self - need for independence - social attention and social relationships - creativity - personal ranking Democrat) has high-schoolers in the city of Abha and to be the arithmetic average of the delay school has high-schoolers in the city of Abha reached (2.94) any degree of spread(the average), as the average arithmetic the general degree of self-realization of students at the secondary level in the city of Abha (3.51) of any degree (large). There are statistically significant differences at level (0.05) between the average scores of the reasons for the delay school by different year of study in the direction of the second-grade students of secondary

The lack of statistically significant differences between the average scores of the reasons for the delay school according to the variable of specialization, as well as the presence of statistically significant differences for self-realization as the abduction of the school year for students of first grade secondary, in addition to the presence of statistically significant differences between the average scores of self-realization of students at the secondary level in the city 
of Abha as a variable in the direction of the student's scientific specialty, and finally having a great impact and statistical significance of independent variables (reasons for delay study) on the dependent variable (selfrealization).

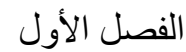
خلفية الدراسة ومشكلتها

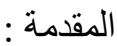

يشهـا العصر الذي نعيشـه تقدماً سريعاً وكبيراً في مختلف ميادين البحث العلمي، والتقدم

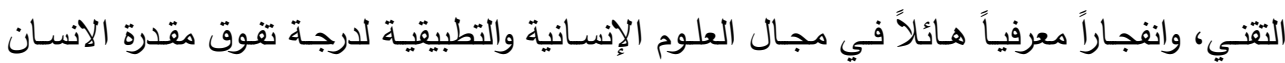
الإدراكية على استيعاب وتذكر المعارف والحقائق العلمية .

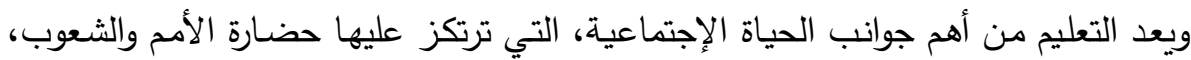

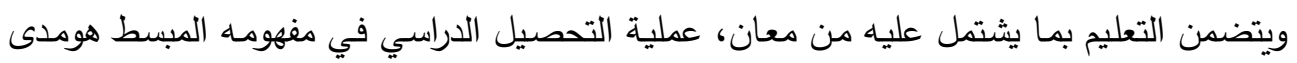

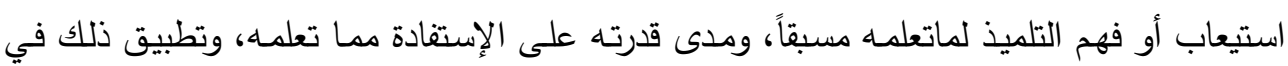

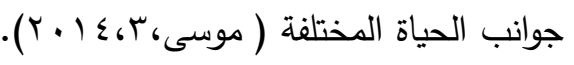
وتواجه العملية التعليمية بعض المشكلات التربوية أثناء أداء رسالتها، وتحقيق أهدافها على هلى هله الوجه الأكمل، ومن بين هذه المشكلات مشكلة التأخر الدراسي. وبالتالي فإن تحقيق الذات ليس ذا قيمة شخصية للفرد فحسب وإنما لـه أهمية على المحيط

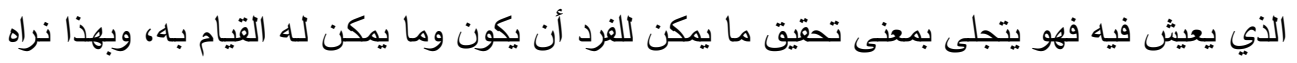

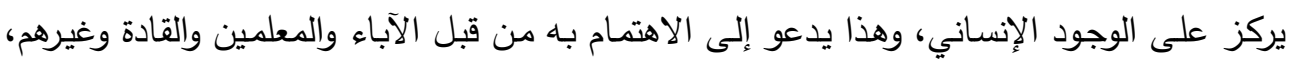

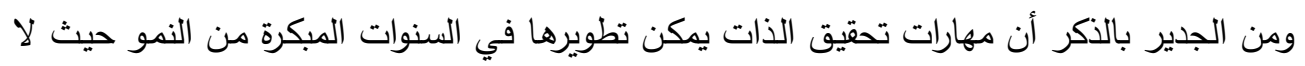

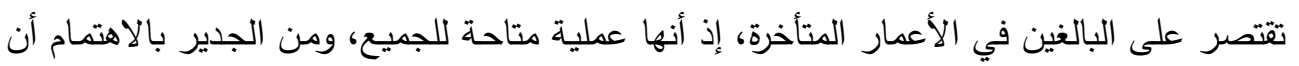

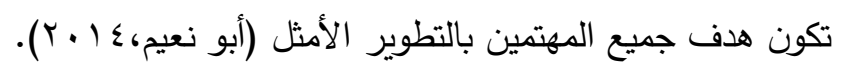

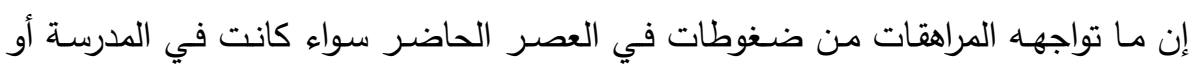

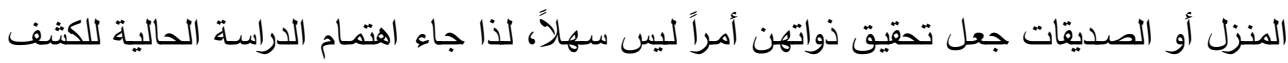
عن التأخر الدراسي وعلاقته بتحقيق الذات على عينة من طالبات المرحلة الثانوية في مدينة أبها بمنطقة عسير . بن 
مشكله الدر اسة وتساؤ لاتها:

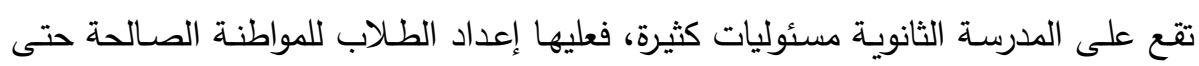

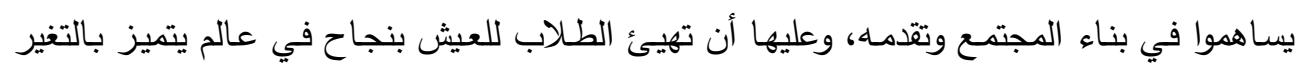
والتطور السريع كما أن عليها أن تعدهم لمواصلة تعليمهم في الجامعات والمعاهد العليا، ولكي تقوم بـاهي

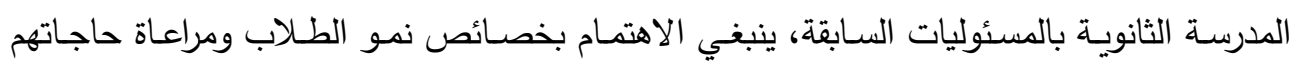

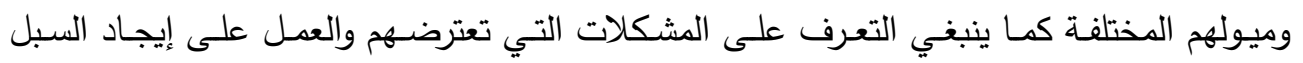

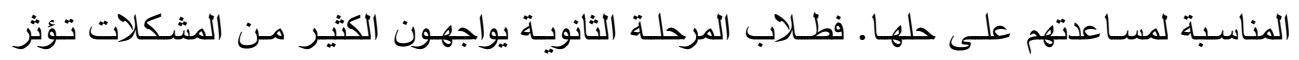

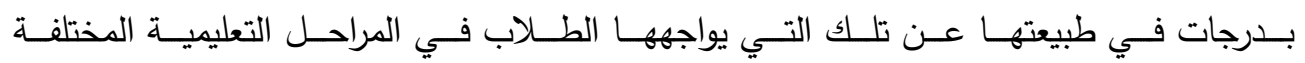

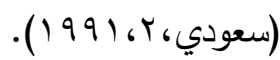

ومن تلك المشكلات مشكلة التأخر الدراسي حيث تعتبر مشكله التأخر الدراسي من المشاكل

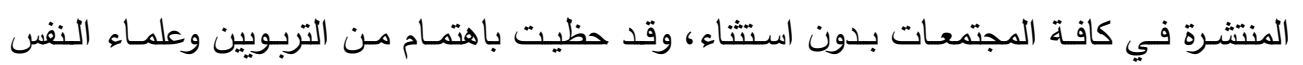
والمدرسين، واعتبروها من أهم المشكلات العصرية التي تعتبر مصدراً لإعاقة النمو والتقدم للحياة

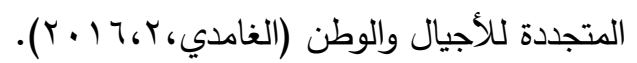
وتسعى الباحثة في الدراسة الحالية للكثف عن درجه العلاقة بين التأخر الدراسي وعلاقتته

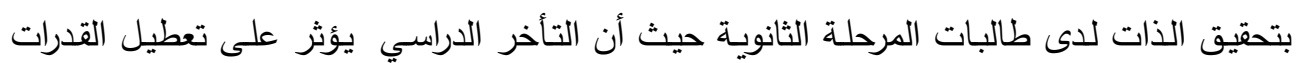

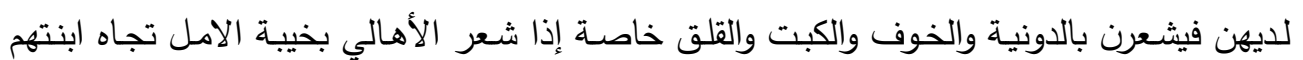
فينعكس ذلك على الطالبة حيث تثعر بالنقص والذنب أمام الجميع مما يؤثر سلبا على تحقيق ذاتها حيث تثعر الطالبة بعدم تحقيق ذاتها فتحتقر نفسها وتقلل من ذاتها خاصـة أمام زميلاتها فقد تقدمنا وهي مازالت متأخرة عنهم ولذلك تسعى الدراسة الحالية في الإجابة عن السؤال الرئيس: ما العلاقة بين التأخر الدراسي وتحقيق الذات لدى طالبات المرحلة الثانوية بمحافظ أبها بمنطقة عسير؟ الإنها ويتفرع عنه الأسئلة الاتية:

ا-ما درجة انتشار اسباب التأخر الدراسي لطالبات المرحلة الثانوية في مدينة أبها؟ r-ما درجة تحقيق الذات لطالبات المرحلة الثانوية في مدينة أبها؟ r- هل توجد علاقة بين التأخر الدراسي وتحقيق الذات لطالبات المرحلة الثانوية في مدينة أبها ؟

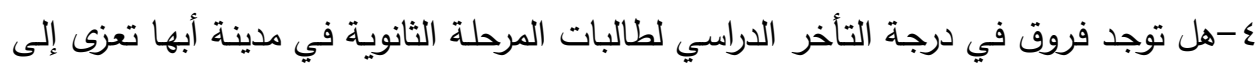
(التخصص - الصف الدراسي)؟ 
ه- هل توجد فروق في درجة تحقيق الذات لطالبات المرحلة الثانويـة في مدينة أبها تعزى إلى

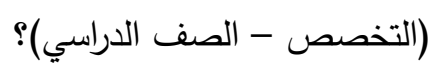

4-هل يمكن التتبؤ بتحقيق الذات من خلال التأخر الدراسي للمرحلة الثانوية في مدينة أبها ؟

أهداف الدراسة:

$$
\text { تهدف الدراسة الحالية إلى التعرف على: }
$$

•الكثف عن العلاقة بين التأخر الدراسي وتحقيق الذات لدى طالبات المرحلة الثانويـة في

$$
\text { مدينة أبها. }
$$

•الكثف عن درجة انتشار التأخر الدراسي لطالبات المرحلة الثانوية في مدينة أبها.

$$
\text { •الكثف عن درجة تحقيق الذات لطالبات المرحلة الثانوية في مدينة أبها. }
$$

•الكثف عن الفروق في درجة التأخر الدراسي لدى طالبات المرحلة الثانوية في مدينة أبها

$$
\text { تعزي إلى (التخصص - الصف الدراسي). }
$$

•الكثف عن الفروق في درجة تحقيق الذات لدى طالبات المرحلة الثانويـة في مدينة أبها

$$
\text { تعزى إلى (التخصص - الصف الدراسي). }
$$

•إمكانية التتبؤ بتحقيق الذات من خلال التأخر الدراسي للمرحلة الثانوية في مدينة أبها.

$$
\text { أهمبة الدراسة }
$$

ا-تكمن أهمية الدراسة الحالية في معرفه العلاقة بين التأخر الدراسي وتحقيق الذات كظاهرة تربوية نفية تحتل مكاناً بارزاً في العمل التعليمي إذ أن المرحلة الثانوية تتطلب إدراكاً خاصاً

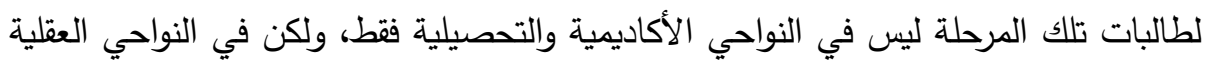

$$
\text { والنفسية والاجتماعية والأخلاقية. }
$$

r-تتبع أهمية الدراسة من إلقاء الضوء على تحقيق الذات لأى طالبات المرحلة الثانوية، وتأثيره

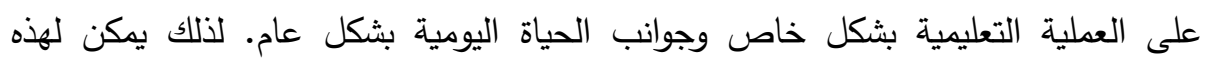

$$
\text { الدراسة }
$$

r-أن تزود المختصين والقائمين على العملية التعليمية بالمعلومات التي قد تساعد على فهم ومعرفة تحقيق الذات لاى طالبات المرحلة الثانوية. وبالتالي الوقوف على تحقيق الذات

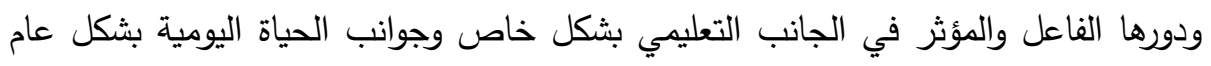
لاى عينه من طالبات المرحلة الثانوية. 
ع-أن هذه الدراسة تتناول الطالبات في المرحلة الثانوية وهي مرحلة ذات خصوصية من حيث بدء تكوين الثخصية مما يتطلب مساعدتهن على اجتياز هذه المرحلة.

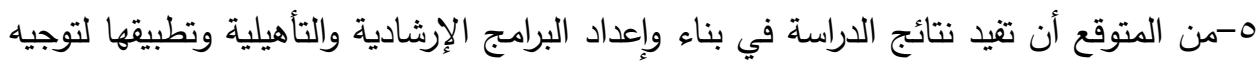
الطالبات المتأخرات دراسياً في المرحلة الثانوية.

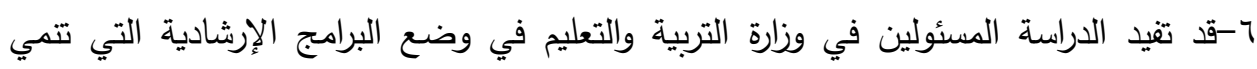
تحقيق الذات.

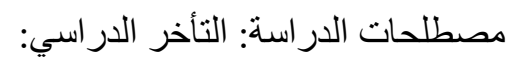
يعرف التأخر الدراسي بأنه حالة نقص في التحصيل، بحيث تنخفض نسبة التحصيل دون

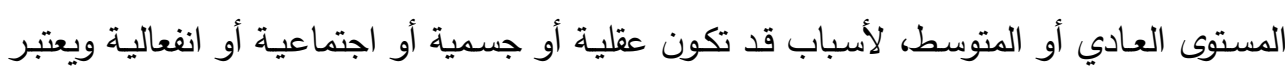
الطالب متأخر دراسياً إذا ظهر ضعفه بوضوح في الدراسة عند مقارنته بغيره من التلاميذ العاديين

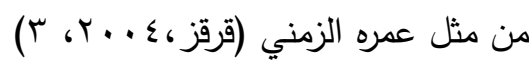
وتعرف الباحثة التأخر الدراسي إجرائياً:

هو كل عائق يواجه الطالبة في مرحلة دراستها سوى كان نفسياً أو أكاديمياً أو اجتماعياً

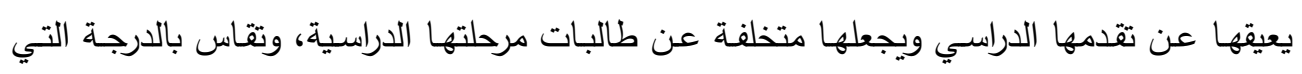
تحصل عليها الطالبة على مقياس التأخر الدراسي المستخدم في الدراسة.

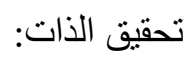

تحقيق الذات هو التحقيق المستمر لإمكانيات الفرد وقدراته ومواهبه وأضاف ماسلو أن تحقيق الذات هو النمو الجوهري في الكائن الحي أو بدقه أكثر هو الكائن الحي الذي يحقق نفسه بنفئه

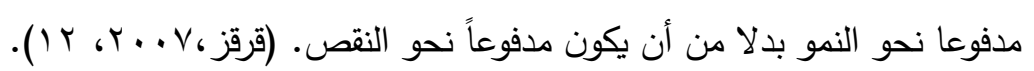
وتعرف الباحثة تحقيق الذات إجرائياً:

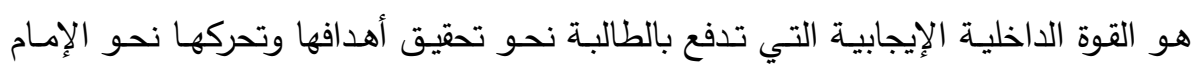

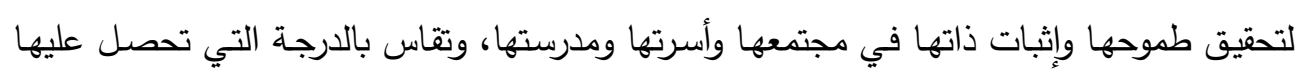
الطالبة على مقياس تحقيق الذات المستخدم في الدراسة. 
تتـاول هذا الفصل الإطار النظري والخلفية العلمية للدراسـة- كأحد الركائز الرئيسـة للبحث العلمي - ويرتبط ارتباطاً مباشراً بموضوعها، وكذلك عرض هذا الفصل للبحوث والدراسات السابقة ذات الصلة بموضوع الدراسة الحالية.

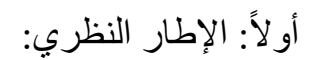

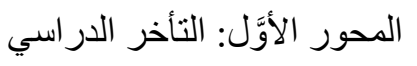

يعد التأخر الدراسي من المشكلات متعدده الأبعاد التي شغلت بال المربين فهو مشكلة نفسية

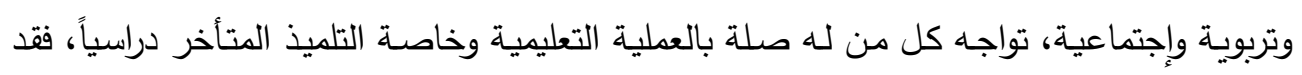

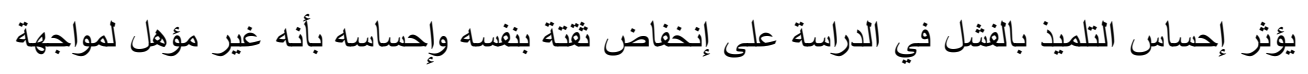

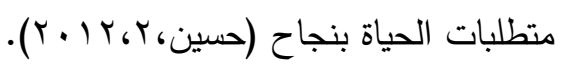

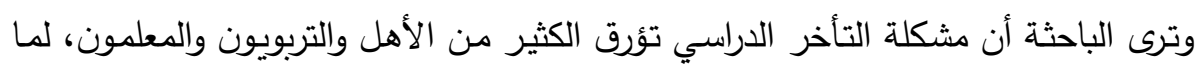
فيها من تأخر في عجلة التمية للفرد والمجتمع والدولة.

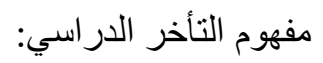
تعد مشكلة التأخر الدراسي مشكلة إنسانية لا تقتصر على بيئة أو مجتمع معين، وإنما تتنثر

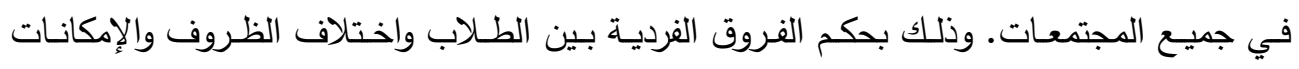

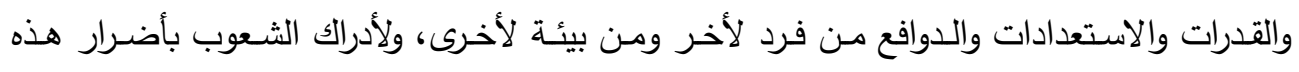

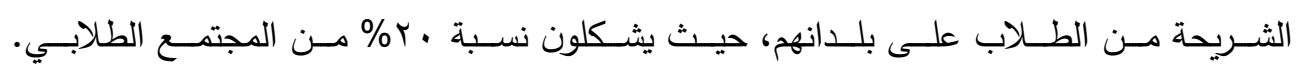

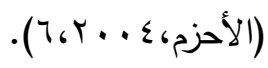

إن مصطلح التأخر الدراسـي يحمل غموضـا وعدم تحديد حتى بين المختصـين أنفسهم،

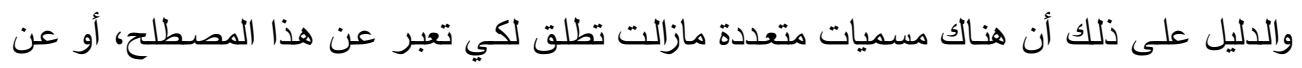
الأفراد الذين تتطبق عليهج هذه الصفة، ولعل ذلك يرجع إلى اختلافهم حول المحكات التي يتخذونها

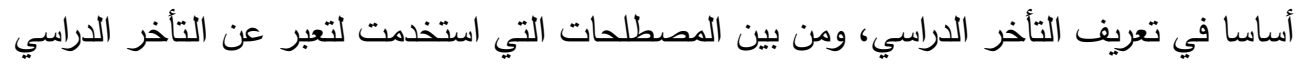

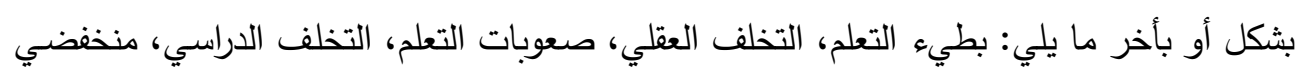
التحصيل، التأخر الدراسي.

أنواع التأخر الدراسي: 


$$
\text { وقد صنف زهران التأخر الدراسي على أساسين كما يلي: }
$$

- تخلف دراسي خاص في مادة بعينها كالحاسب مثلا. ويرتبط بنقص القدين كانس القدرة.

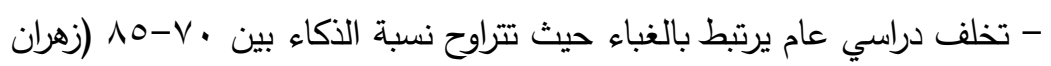

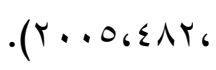

$$
\text { المبحث الثاني: تحقيق الذات: }
$$

إن الثخصية السوية بما تتمتع به من إيجابية هي التي تتيح للحياة الندو والتقدم، إذ تثكل

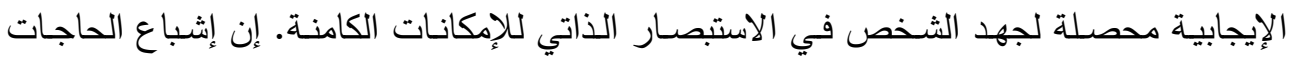
شيء ضروري للثبات والاستقرار النفسي، ويتوقف ذلك على مقدرات الفرد في إشباع حاجاته. ولا

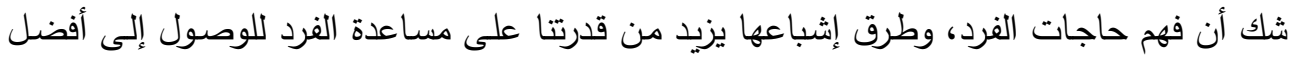

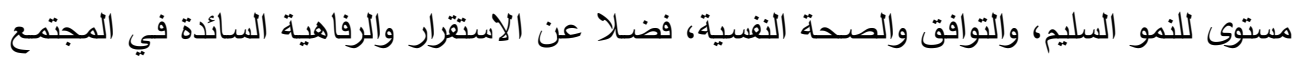

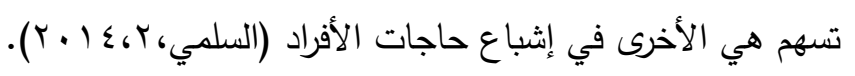

مفهوم الأات: الأات على المستوى اللغوي:

يحاول الإنسان على الدوام تحقيق إمكاناته الكامنة والأصلية بكل ما يحتاج لـه من طرق، ويمثل هذا المفهوم عنده الدافع الرئيسي، والحقيقة الوحيدة لدى الكائن العضوي، وكل الدوافع الأخرى

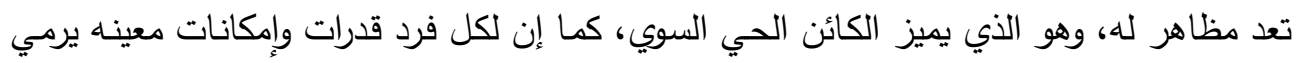

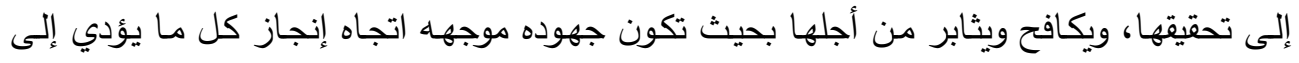

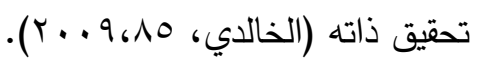

\section{العوامل المؤثرة في تكوين تحقيق الذات:}

1-العوامل الذاتية: مثل صورة الفرد ومظهره، حيث أنهما عاملان مهمان جداً في نفسية الفرد

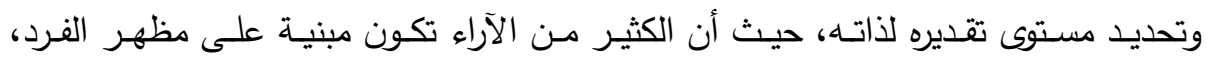

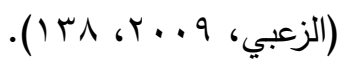

ץ-العوامل الخارجيـة: وتتحد تلك العوامل البيئية في حدين وهما الأسرة والبيئة حيث يوضحها

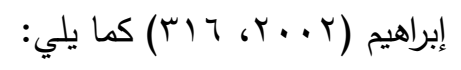

أ- الأسـرة: تعتبر الأسرة العامل الأسـاس في التتشئة الاجتماعيـة للفرد فبدونها لا نستطيع أن نحصل على شخصية تتمتع بتقدير ذات عالٍ، فيبدأ تكوين شخصية الفرد نتيجة الجو الأسري

$$
\text { والتربية التي يتلقاها على أيدي أبويه. }
$$


ب- المدرسة: كما تعد المدرسة أحد العوامل المؤثرة في تقدير الذات لدى الفرد، لما لها من دور تربوي قوي في نفس الطفل حيث أن أسلوب النمذجة والقدوة عند الطفل يؤثر في تقديره لذاته

$$
\begin{aligned}
& \text { من خلال الفكرة التي تتكون لديه عن قدراته. } \\
& \text { النظريات المفسرة لتحقيق الأت: }
\end{aligned}
$$

نظرية الذات لاى روجرز: وتعتبر نظرية الذات لكارل روجرز هي أحدث وأشمل نظريات

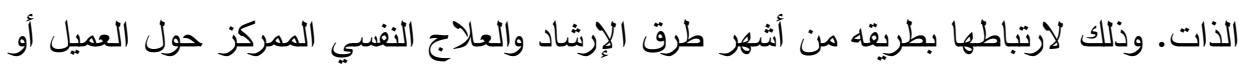
غير الموجه. وقد بينت أساسا هذه النظرية على دراسات وخبرة روجرز في الإرشاد والعلاج النفسي.

نظرية الذات يونغ (yung): ويرتبط تحقيق الذات بالإنجاز والتحصيل والتعبير عن الذات،

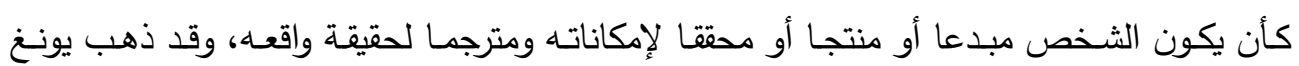
(yung) الغائي ) وأثـار إلى التطور المتصـاعد لدى الكائنات البشرية لتحقيق مستوى أكثر متكاملا، وأن الماضي والمستقبل يؤثران معا في مدى تحقيق الوجود الذاتي للنفس كما يرى إن تحقيق النموذج

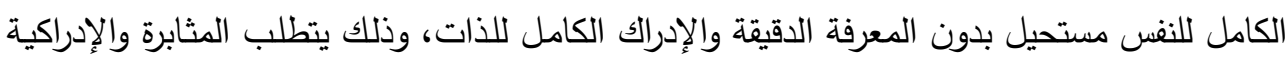
(Engler,2006) الدقيقة

نظربـة أربكسـون Erikson: :قد أشـار أريكسون إلى تأثيرات المجتمع على الفرد تكون أساسية وليست جانبية لتطور الثخصية، لذلك فهناك علاقة بين التنظيم الخارجي والداخلي وأن الاختلاف في المتغيرات الحضارية تكون مؤثره وتقود إلى اختلاف في تصرفات الفرد، كما أكد دور

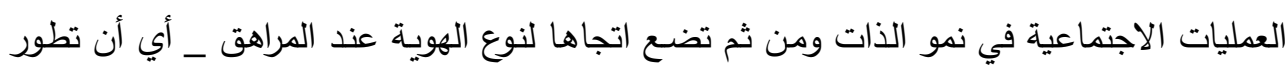

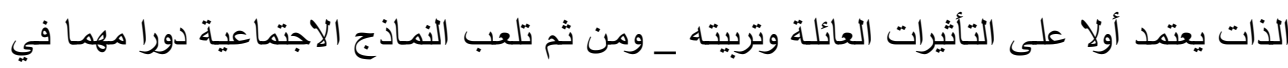
ذلك، أي أن الهوية بشكل مختصر نتاج اجتماعي نفسي، لقد طور أريكسون نظرية في النمو النفسي

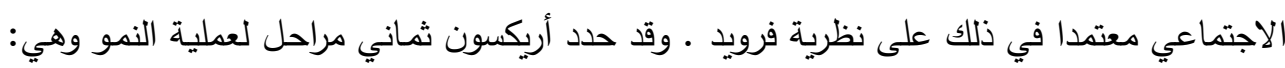
مرحلة الثقة وتقابلها عدم الثقة، مرحلة الاستقلال مقابل الثكك والخجل، مرحلة المبادأة مقابل الثعور

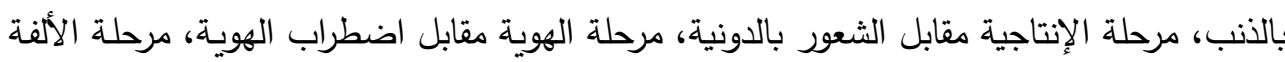

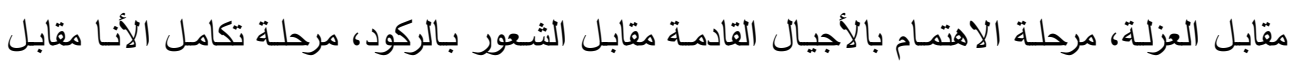

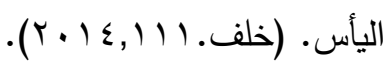


نظريـة كسوبر سـميث (Coopersmith,1976): تمثلت أعمـال كوبر سميث في دراسـة

تحقيق الذات، حيث تتضمن نظريته:

أ- تحقيق الذات الحقيقي: ويوجد في الأفراد الذين يشعرون بالفعل أنهم ذو قيمة.

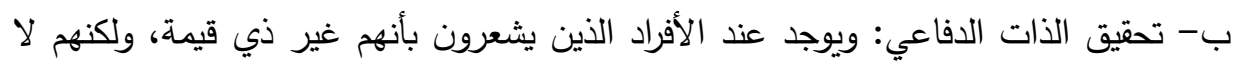

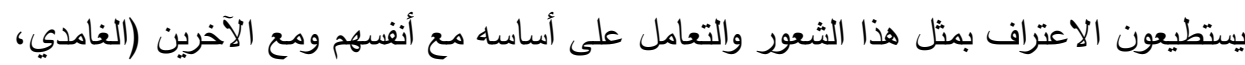

.$(r \cdot 9$

$$
\text { تحقيق الذات في الإسلام: }
$$

إن الإسـلام مـنهج شـامل للحيـاة يحقق للنـاس السعادة والطمأنينـة والرضـا، ويرشـدهم على الإسى

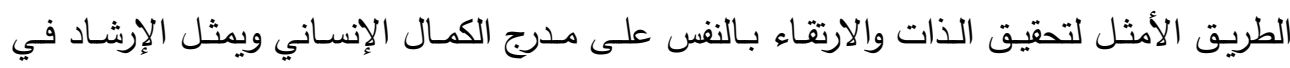

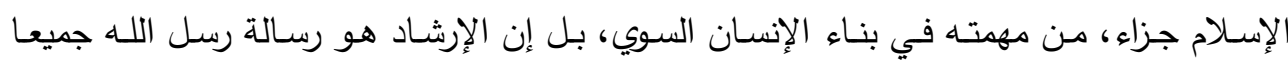

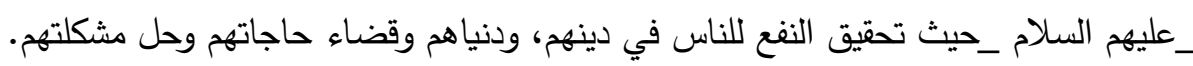

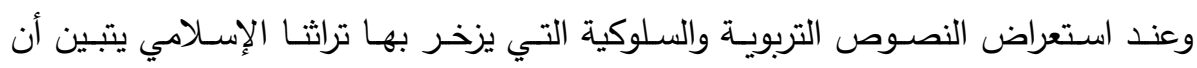

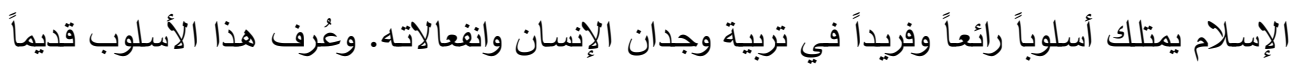

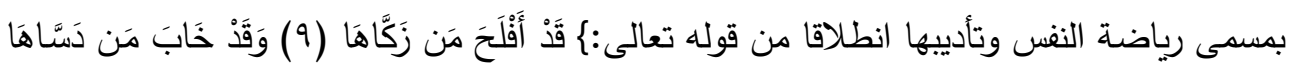

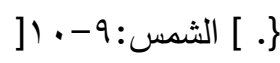

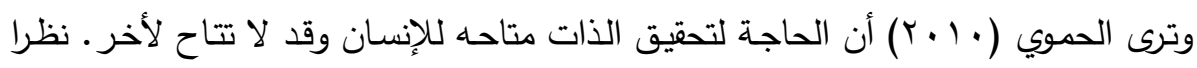
لأن: إشباعها يتطلب قدره عقلية خاصـة في مجال من مجالات الحياة. فإن دافعيـة التزكي توجد مصادرها داخل فطره الإنسان. المبحث الثالث: المرحلة الثانوية: التعليم الثانوي هو المرحلة الأخيرة من التعليم المدرسي، يسبق هذه المرحلة التعليم الأساسي

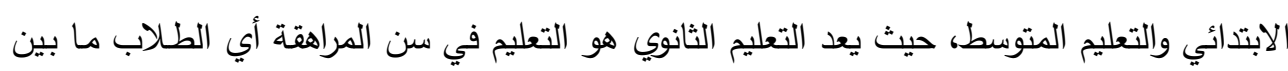

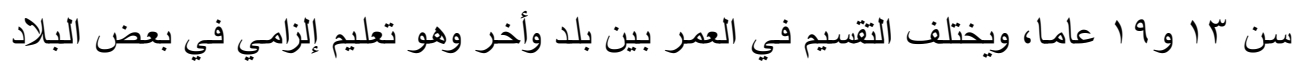
وليس كلها. (ويكبيديا التعليم الثانوي). مفهوم التعليم الثانوي: ماني

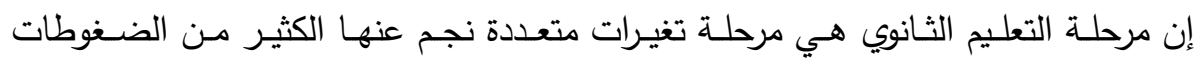
والأزمات النفسية التي يصعب على المراهق التعامل معها، وإن تركـه لوحده يكون فريسـة سهله

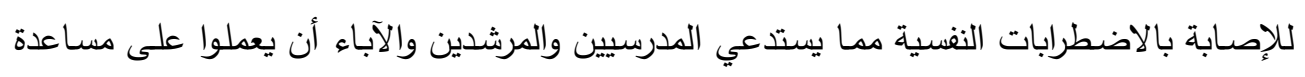


هؤلاء الطلبة في التعامل مع مشكلاتهم بطرق فعاله ومنتجه. وتقسم الضغوط النفسية لاى طلاب

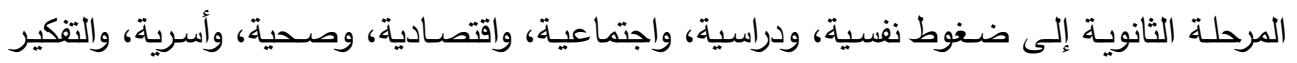

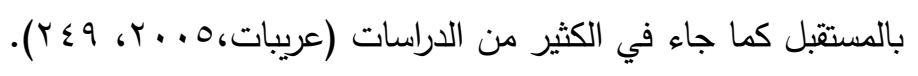

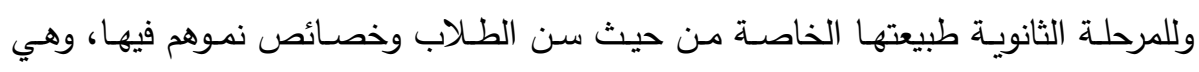

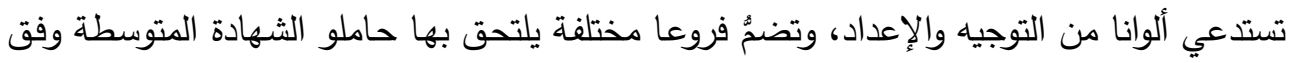

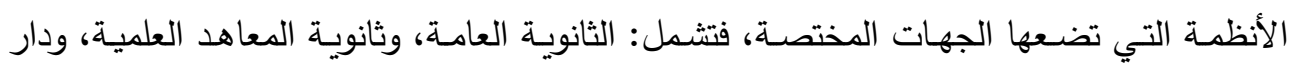
التوحيد، والجامعة الإسلامية، ومعاهد إعداد المعلمين والمعلمات، والمعاهد المهنية بأنواعها المختلفة (من زراعية وصناعية وتجارية)، والمعاهد الفنية والرياضية، وما يستحدث في هذا وذا المستوى. أهداف التعليم الثانوي في المملكة العربية السعودية:

أشـارت وثيقة سياسـة التعليم في المملكة العربية السعودية الصـادرة عن وزارة التعليم للعام

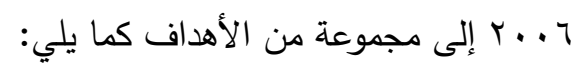

() بناء الثخصية القادرة على مواجهة المستقبل مع التأكيد على الهوية الثقافية الوطنية والإسلامية دون تعصب يرفض تطور الفكر العالمي.

r إعداد الطالب القادر على الابتكار والتجديد والتحليل بتزويده بالمهارات الفكرية والعقلية اللازمة لعملية التعلم الذاتي.

r) ترسيخ القيم الدينية والسلوكية في نفوس الطلبة والكثف عن استعدادات وقدرات ومهارات الطلاب والعمل على تتميتها.

ع) إعداد الطالب لمواصلة تعليمه العالي والجامعي تحقيقاً للتمية الثاملة. 0) الاهتمام برعاية الطلبة الفائقين وإتاحة الفرصة للموهوبين منهم بصقل مواهبهم وتتمية قدراتهم. 7) إكساب الطلبة المفاهيم العملية الإنسانية في حياة هذا العصر لتسخيرها لخدمة المجتمع. Vتيمية تقدير المسؤولية والعمل على أن يدرك الطالب ماله من حقوق وما عليه من واجبات. ^)تمية المهارات والميول والقدرات الخاصة مع إكساب الطالب حاسة التذوق الفني. 9)/التعرف على حاجات المجتمع وإعداد جيل يسهم مساهمة فعالة في النهوض بالمجتمع وتطوره.

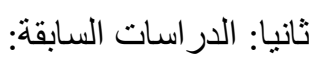


تتناول الباحثة في هذا الفصل الدراسات العربية والأجنبية التي بحثت في التأخر الدراسي وتحقيق الذات وقد صنفت هذه الدراسات والبحوث وفقا للمتغيرات التي تتاولتها الدراسة على النحو

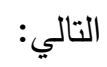

•دراسات تتاولت التأخر الدراسي وعلاقته ببعض المتغيرات.

•دراسات تتاولت مفهوم تحقيق الذات وعلاقته ببعض المتغيرات.

$$
\text { المحور الأول: دراسات تناولت التأخر الدراسي }
$$

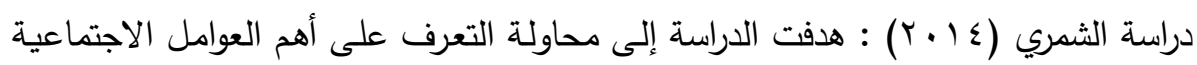

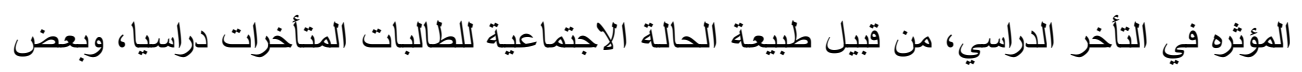

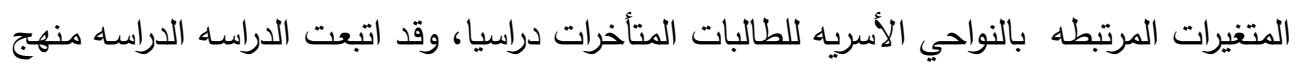

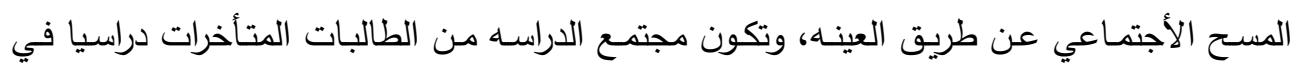

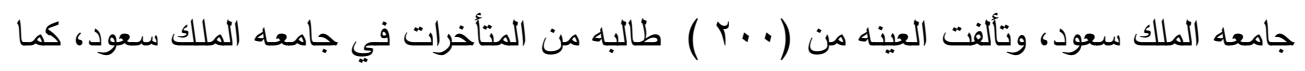

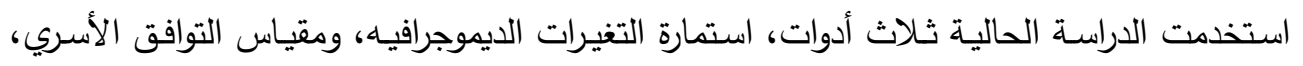

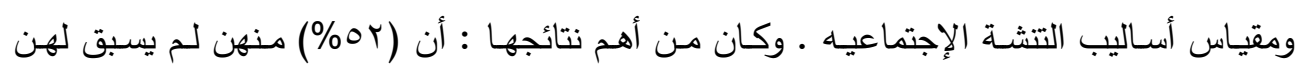

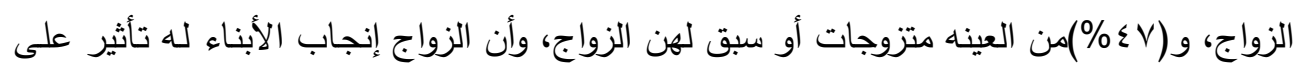

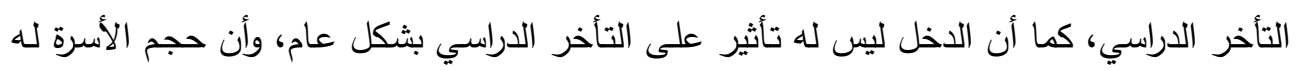

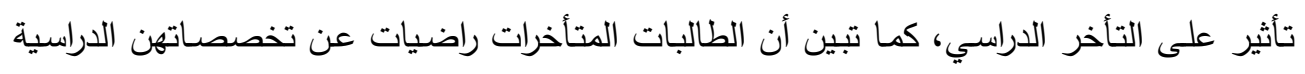

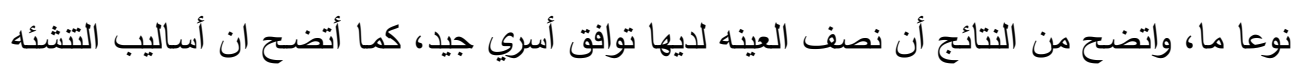

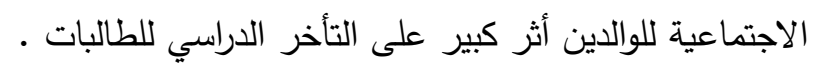

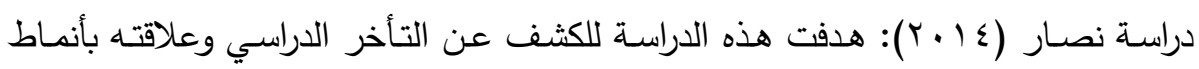

السلوك المشكل كما يقدرها المعلمون لدى طلبة المرحلة الثانوية في منطقة الجليل الأسفل، وتحقيق ونديق

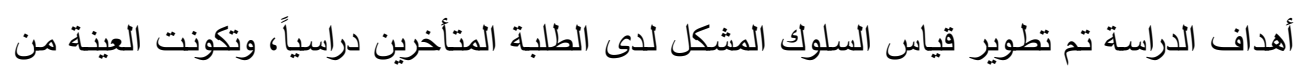

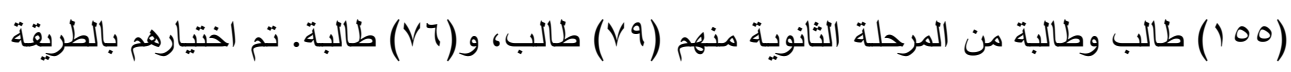
الميسرة وأظهرت النتائج أن مدى انتشار أنماط السلوك المشكل لدى طلبة المتأخرين دراسياً، جاء

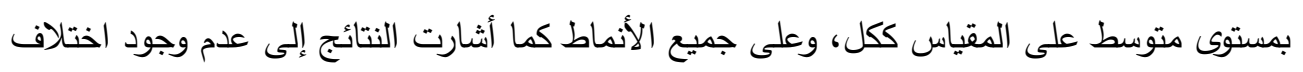

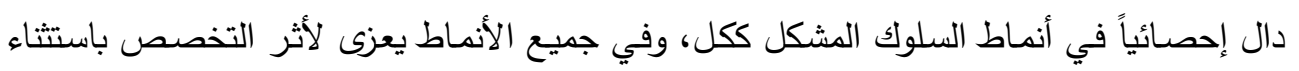

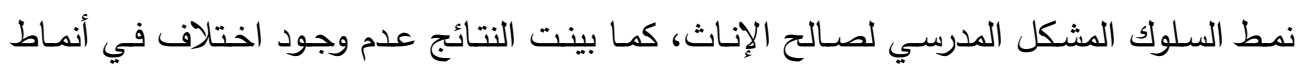
السلوك المشكل ككل، وفي جميع الأنماط يعزى لأثر الجنس، كما أظهرت نتائج الدراسة عدم وجود الأبان 
علاقة ارتباطية دالة إحصائية بين التحصيل الدراسي والسلوك المشكل ككل، وجميع الأنماط لدى الطلبة المتأخرين دراسياً.

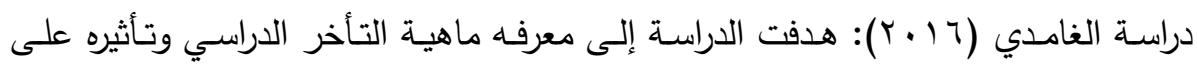
الأطفال في المرحلة الابتدائية من وجهه نظر التربويين والعاملين في مجال علم النفس. وتم اختيار

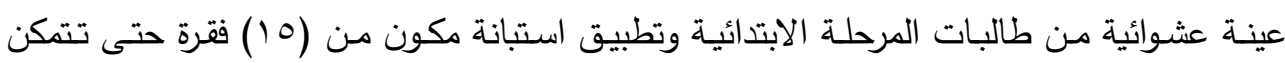

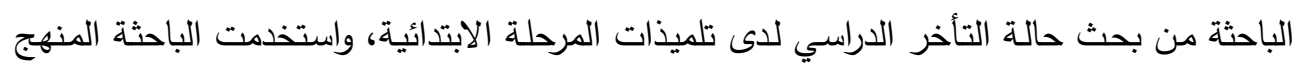
الوصفي التحليلي وكانت نتائج الدراسة وجود فروق دالة إحصائية بين أفراد العينة في مشكلة التأخر الدراسي وأسبابها وأنواعها وبعض الحلول لهاب لها، وكذلك هناك علاقة ذات دلالة إحصائية بين أفراد

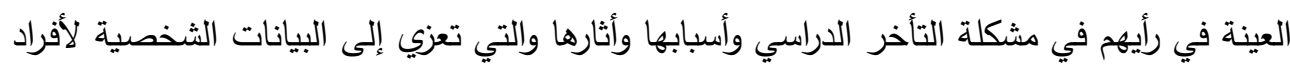
العينة المحور الثاني: دراسات تناولت تحقيق الذات

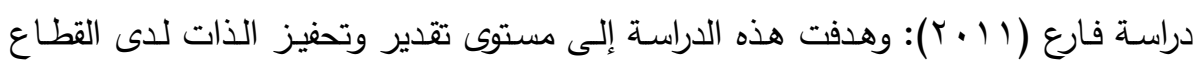

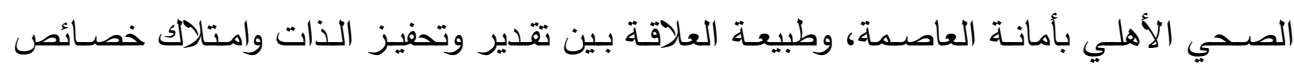

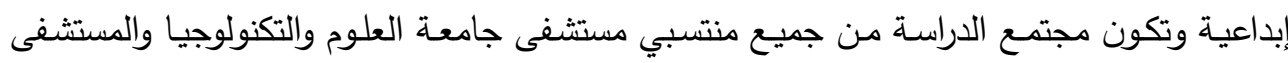

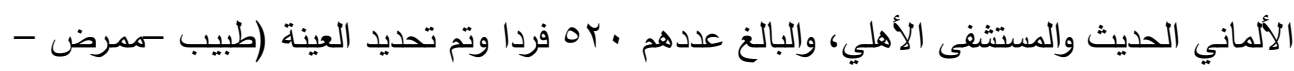

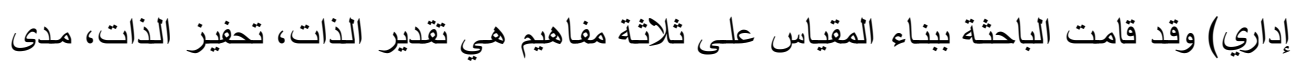

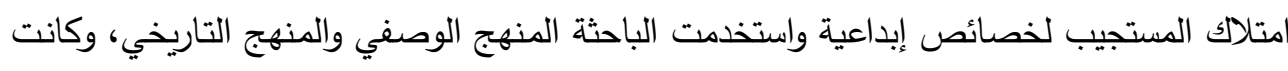

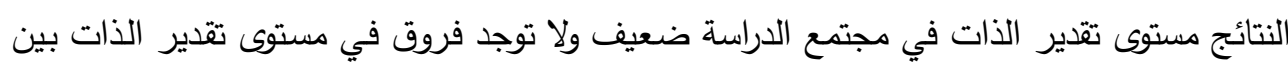

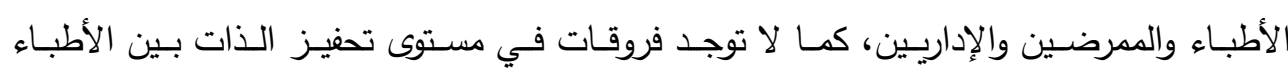

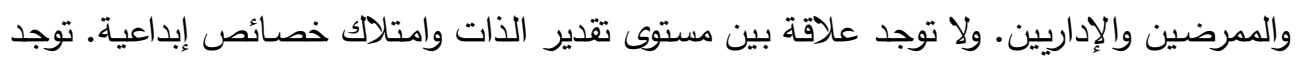

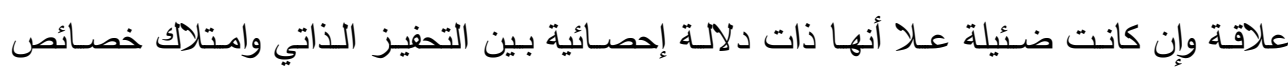

دراسة السلمي (ع ( ب): وهدفت إلى إعداد برنامج إرشادي قائم على الإرشاد غير الموجة

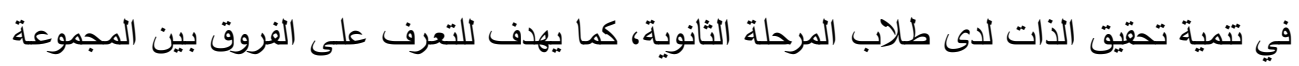

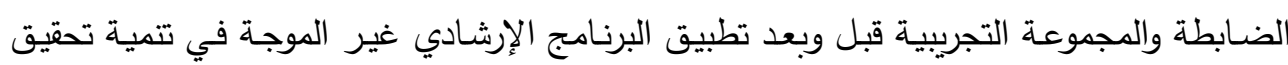

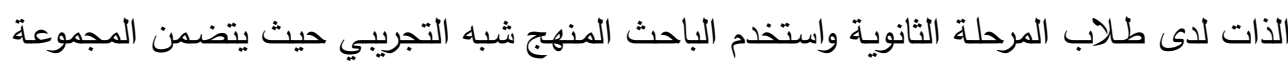

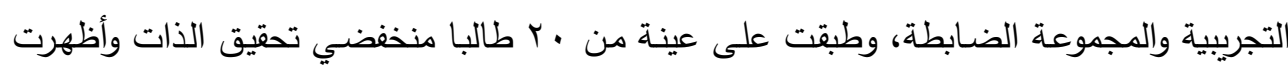


النتائج وجود فروق بين المجموعتين الضـابطة والتجريبية في تحقيق الذات، بعد تطبيق البرنامج

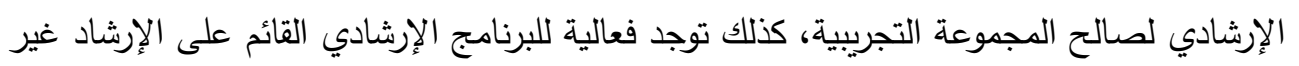

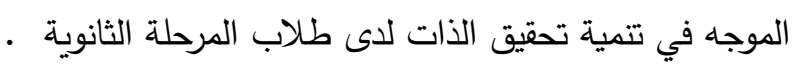

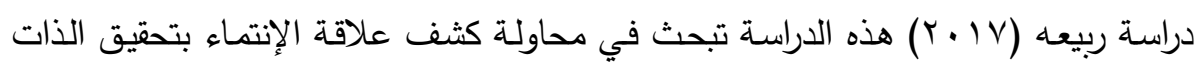

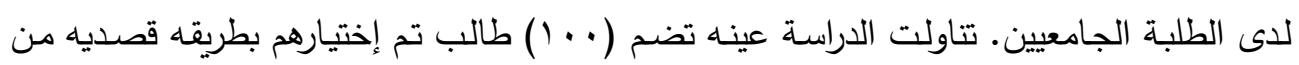

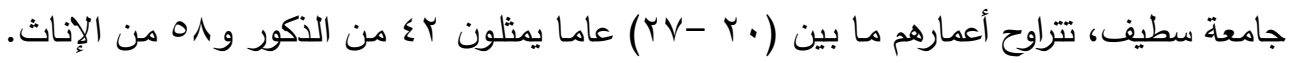

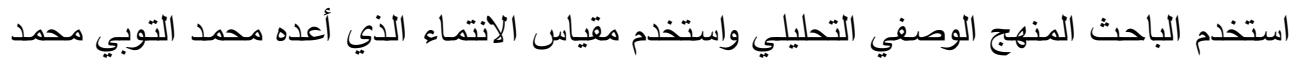

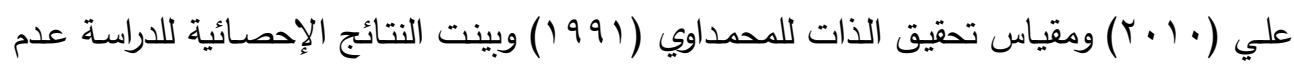

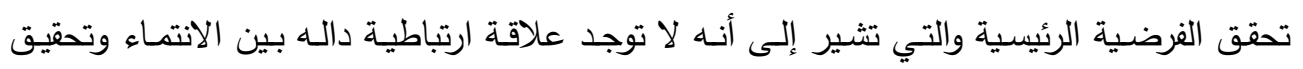
الذات. كما بينت المستويات المرتفعة لتحقيق الذات، والمستويات المتوسطة للانتماء، وأبعاده خاصة التهاء

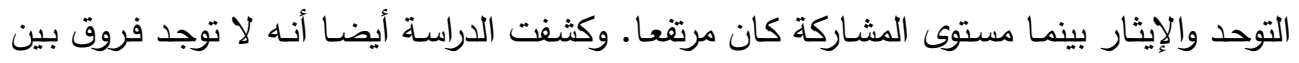
الذكور والإناث فيما يتعلق بالانتماء وتحقيق الذات. الفصل الثالث: منهج الاراسة وإجراءاته

في هذا الفصل تم تحديد منهج الدراسة المناسب، ومجتمع وعينة الدراسة، والإثشارة إلى أداة الدراسة المستخدمة وخطوات إعدادها وطريقة التأكد من الخصائص السيكومترية للأداة والتي تمثلت

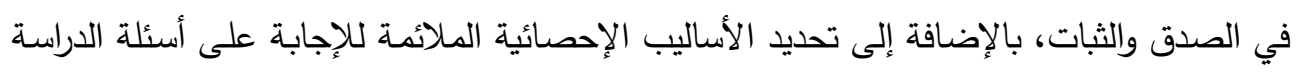
والتحقق من صحة الفروض الإحصائية. منهج الدراسة

تم تحديد المنهج الوصفي والذي يعتمد على دراسـة الظـاهرة كما توجد في الواقع ويهتم بوصفها وصفاً دقيقاً، ويعبر عنها تعبيراً كيفياً أو كمياً، فالتعبير الكيفي يصف دران لنا الظاهرة ويبين

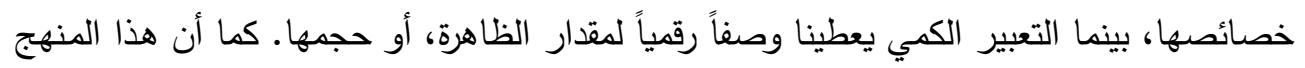
لا يقتصر على جمع البيانات وتبويبها وإنما يمضي إلى ما هو أبعد من ذلك لأنه يتضمن قدراً من التفسير لهذه البيانات.

مجتمع الدر اسة: 
تكـون مجتمـع الإراسـة مـن جميـع طالبـات المرحلــة الثانويـة في مدينـة أبهـا خـلال الفصـل

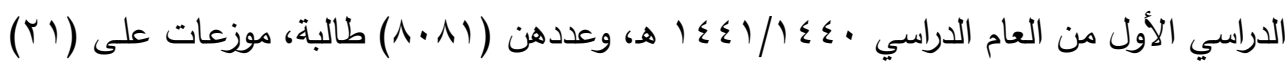

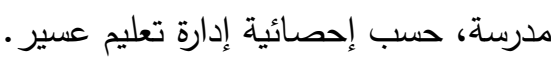

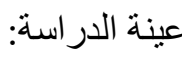

•تم التطبيق أولا على عينة استطلاعية تكونت من (·०) طالبة، بواقع (• () طالبات من (أول ثانوي، ثاني ثانوي علمي، ثاني ثانوي شرعي، ثالث ثانوي علمي، ثالث ثانوي شرعي) بهدف التأكد من الخصائص السيكومترية لأدوات الدراسة (الصدق والثبات)، وسوف يرد لاحقا تتاول (الصدق والثبات) تفصيليا. أدو ات الدر اسة في صورنها النهائية

بعـد التأكد مـن تـوافر الصـدق والثبـات لأدوات الدراسـة، تأكدت الباحثـة مـن صـلاحيتهما

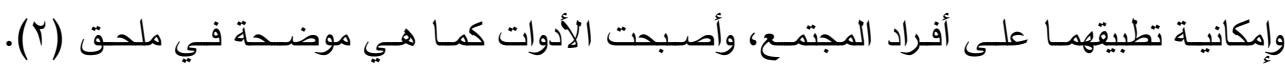
واشتملت على:

\section{الجزء الأول: بيانات أولية}

اشتملت على (اسم الطالبة "اختياري" - السنة الدراسية - التخصص).

الجزء الثاني: مقياس أسباب التأخر الدراسي اشتمل على (§؟) عبارة توزعت على (0)

•البعد الأول: العوامل النفسية "A" عبارات من (1 - ^) أبعاد كالتالي: - n

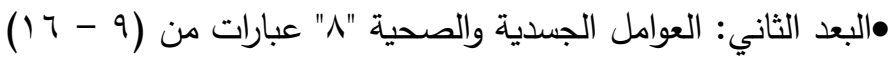

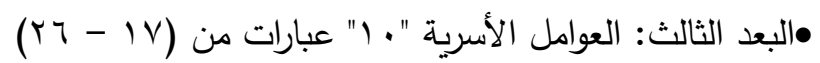

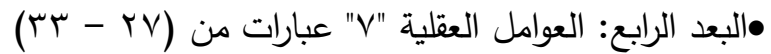

•البعد الخامس: العوامل التعليمية والتعلمية "الا" عبارة من (ع ب - ع ؟) الجزء الثالث: مقياس تحقيق الذات اشتمل على (70) عبارة توزعت على (^) أبعاد كالتالي:

•البعد الأول: الإدراك العالي للحقيقة "r ا" عبارة من (1 - Y I )

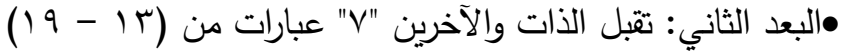

•البعد الثالث: التلقائية والبساطة "ه" عبارات من (•r - ؟ ع)

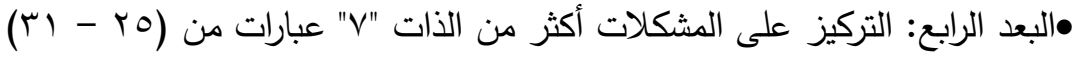

•البعد الخامس: الحاجة إلى الاستقلالية "ه" عبارة من (rr - بrم) 


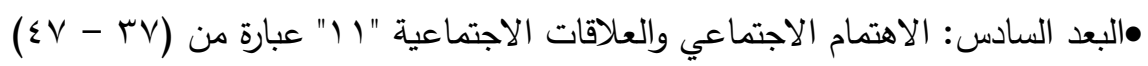

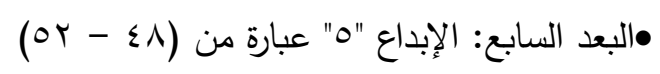

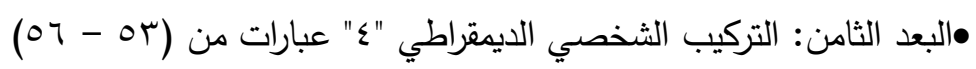
تصحيح أدوات الدر اسة

بناء على اقتراح المحكمين تم استخدام مقياس ليكرت الخماسي المتدرج لتصحيح استجابات

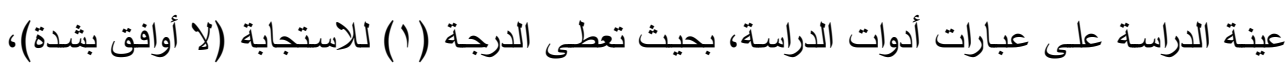

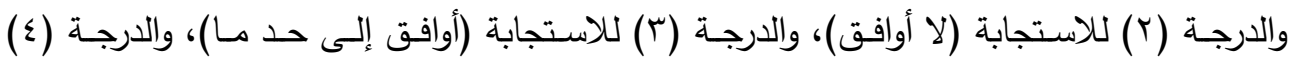

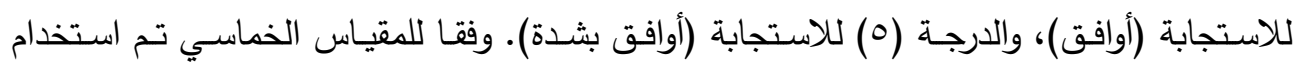

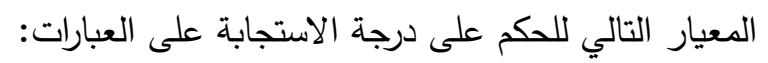

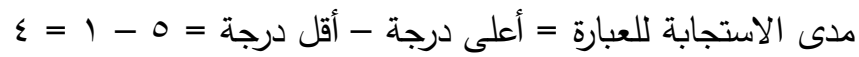

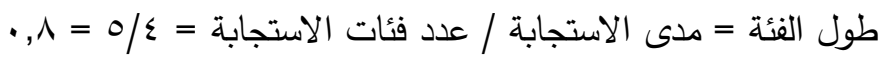
جدول (V): معيار الحكم على المتوسطات الحسابية لأدوات الدراسة

\begin{tabular}{|c|c|c|}
\hline الدرجة & الاستجابة & الحسابي المتوسط \\
\hline ضدا & لا أوافق بشدة & $1, \wedge \cdot-1$ \\
\hline ضعيفة & لا أوافق & $r, r .-1, \lambda)$ \\
\hline متوسطة & أوافق إلى حد & $r, \varepsilon \cdot-r, r)$ \\
\hline كبيرة & أوافق & $\varepsilon, r \cdot-r, \varepsilon)$ \\
\hline كبيرة جدا & أوافق بشدة & $0-\varepsilon, Y)$ \\
\hline
\end{tabular}

الفصل الر ابع عرض ومناقشة النتائج وتفسير ها في الفصل الحالي تمت الإجابة على أسئلة الدراسة والحصول على النتائج ثم محاولة مناقثة وتفسير هذه النتائج وإظهار مدى اتفاقها أو اختلافها مع الدراسات السابقة، وذلك على النحو التالئي:

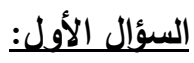

ما درجة انتشار أسباب التأخر الدراسي لاى طالبات المرحلة الثانوية في مدينة أبها؟

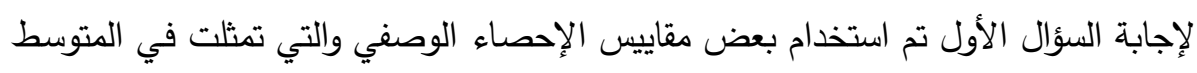
الحسابي والانحراف المعياري والترتيب لكل بعد من أبعاد أسباب التأخر الدراسي (العوامل النفسية - 
العوامل الجسدية والصـحية - العوامل الأسرية - العوامل العقلية - العوامل التعليمية والتعلميـة)، كذلك حساب المتوسط الحسابي العام والانحراف المعياري العام لجميع الأبعاد والذي يمثل الدرجة الأبراه الكلية لمقياس أسباب التأخر الدراسي، وتم الحصول على النتائج التالية: جدول (^): المتوسطات الحسابية والانحرافات المعيارية والترتيب لأسباب التأخر الدراسي التي التئي لاى طالبات المرحلة الثانوية بمدينة أبها

\begin{tabular}{|c|c|c|c|c|}
\hline الترتي & الانتشار & الانحراف & الحسابي & البعد البع \\
\hline r & متوسطة & $\cdot, 71$ & $r, 9 \varepsilon$ & الأول: العوامل النفسية \\
\hline$\varepsilon$ & ضعيفة & $\cdot, 7 \leqslant$ & r, r & الثاني: العوامل الجسدية \\
\hline 。 & ضعيفة & זדו, & $r, 10$ & الثالث: العوامل الأسرية \\
\hline 1 & كبيرة & r & $r, 01$ & الرابع: العوامل العقلية \\
\hline r & كبيرة & זד, & r,or & الخامس: العوامل التعلمية \\
\hline & متوسطة & $\cdot, 07$ & $r, q$. & الدرجة الكلية \\
\hline
\end{tabular}

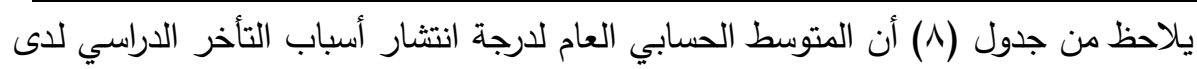

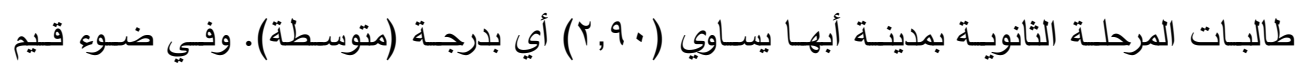
المتوسطات الحسابية لأبعاد أسباب التأخر الدراسي أمكن ترتيبها على النحو التالي: العوامل العقلية

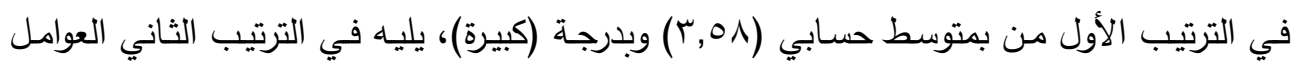

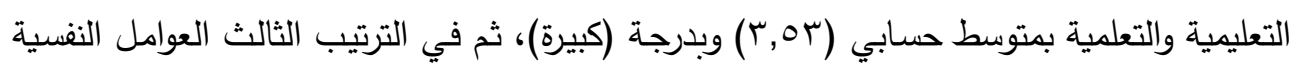

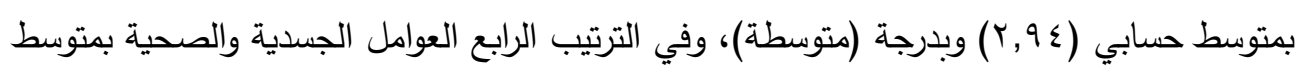

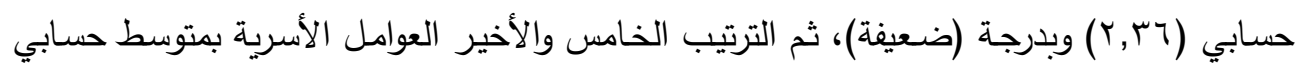

$$
\text { ( }
$$

وفيما يلي وصفا لاستجابات عينة الدراسة على عبارات كل بعد من أبعاد أسباب التأخر الدراسي: البعد الأول: العوامل النفسية 
جدول (9): المتوسطات الحسابية والانحرافات المعيارية لأسباب التأخر الدراسي البعد الأول: العوامل النفسية

\begin{tabular}{|c|c|c|c|c|c|}
\hline \multirow{2}{*}{ 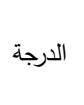 } & الانحراف & المتوسط & 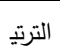 & \multirow{2}{*}{ 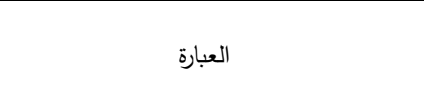 } & \multirow{2}{*}{ م } \\
\hline & 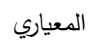 & الحسابي & ب & & \\
\hline كبيرة & 1.46 & 4.18 & 1 & أتمنى أن أجد فرصة للتعبير عن نفسي & v \\
\hline متوسطة & 1.43 & 3.32 & 2 & لم أستطيع تقبل المعلمة & 1 \\
\hline متوسطة & 1.36 & 3.22 & 3 & أشعر بالضيق عند الاستذكار & 。 \\
\hline متوسطة & 1.27 & 2.81 & 4 & أجد صعوبة في التركيز داخل الفصل & r \\
\hline ضعيفة & 1.24 & 2.57 & 5 & أعجز عن تذكر ما طلب مني داخل الفصل & $\varepsilon$ \\
\hline ضعيفة & 1.01 & 2.51 & 6 & فرض على التخصص لذلك لأهتم بدراسته & r \\
\hline ضعيفة & 0.87 & 2.48 & 7 & 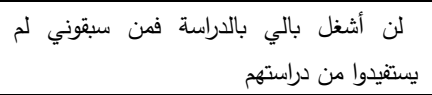 & $\wedge$ \\
\hline ضعيفة & 0.94 & 2.44 & 8 & أشعر أن دراستي ليست مهمة في حياتي & 1 \\
\hline متوسطة & 0.68 & 2.94 & & المتوسط العام & \\
\hline
\end{tabular}

تشير نتائج جدول (9) أن المتوسط الحسـابي العـام لارجـة انتشـار العوامل النفسية كأحد

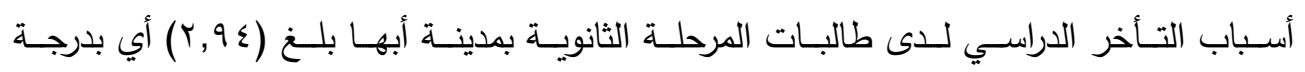

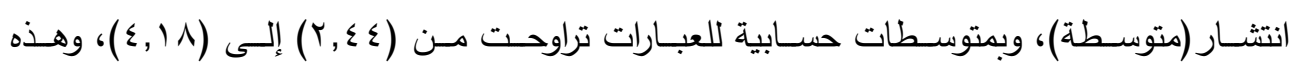

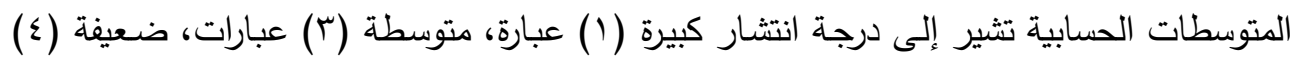
عبارات.

وجاءت أعلى عبارتين على النحو التالي: العبارة "Y" (أتصنى أن أجد فرصـة للتعبير عن

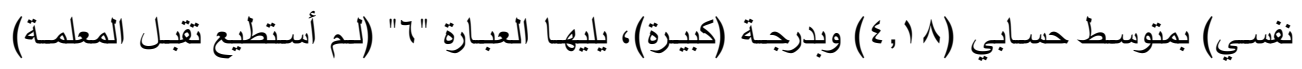
بمتوسط حسابي (r, r,) وبدرجة (متوسطة). وجاءت أقل عبارتين على النحو التالي: العبارة "A" (لن أثغل بالي بالدراسة فمن سبقوني لم الم

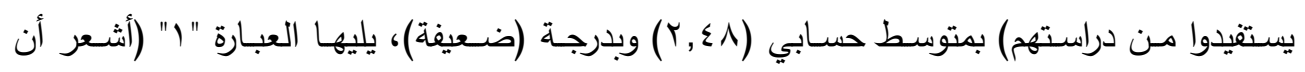

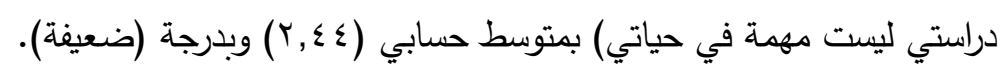
البعد الثاني: العوامل الجسدية والصحية

جدول (• (): المتوسطات الحسابية والانحرافات المعيارية لأسباب التأخر الدراسي البعد الثاني:

\begin{tabular}{|c|c|c|c|c|c|}
\hline \multicolumn{6}{|c|}{ العوامل الجسدية والصحية } \\
\hline الدرج & الانحرا & الهتو & التز & العبارة & 8 \\
\hline
\end{tabular}




\begin{tabular}{|c|c|c|c|c|c|}
\hline \multirow[t]{2}{*}{$\dot{z}$} & ف & سط & تيب & & \\
\hline & المعيار & الحسا & & & \\
\hline متوس & $1, \pi 9$ & r,AT & 1 & الحصص لتاولي لوجبة الإفطار قليلة مما يشعرني بالإجهاد في & $\begin{array}{l}1 \\
r\end{array}$ \\
\hline متوس & $1, \pi 4$ & r, ro & r & داخل الفصل للفراش في وقت متأخر مما يشعرني بالنعاس & ! \\
\hline 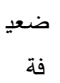 & $1, r 9$ & $r, T$ & $r$ & نشاطي بسيط عند الاستذكار & . \\
\hline ضوض & $1, r 4$ & $r, \varepsilon$ & $\varepsilon$ & داخل الفعر بضعل. عام في جسدي مما يؤثر على نثاطي & $i^{r}$ \\
\hline ضعة - في & 1, ro & $r, r \wedge$ & 。 & قدتي لبذل الجهد للاستذكار ضعيفة & 1 \\
\hline ضبع & $\cdot, \wedge т$ & $r, \cdot \varepsilon$ & 1 & أشعر بالخجل من ضعف البصر لاي & $\begin{array}{l}1 \\
1\end{array}$ \\
\hline ضعة في & $\cdot, 91$ & 1,91 & v & أعاني من مشكلة في السمع & $\begin{array}{l}1 \\
0\end{array}$ \\
\hline 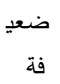 & , vo & $1, \wedge \Lambda$ & $\wedge$ & أعاني من أعاقة جسية & 9 \\
\hline 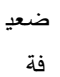 & 0.64 & 2.36 & & المتوسط العام & \\
\hline
\end{tabular}

تشـير نتـائج جـدول ( • () أن المتوسـط الحسـابي العـام لدرجـة انتشـار العوامـل الجسـدية والصحية كأحد أسباب التأخر الدراسي لدى طالبات المرحلة الثانويـة بمدينة أبها بلـغ (جr,Y) أي

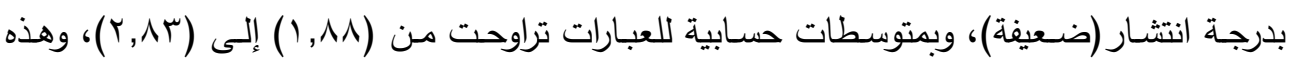
المتوسطات الحسابية تشير إلى درجة انتشار متوسطة (Y) عبارة، ضعيفة (T) عبارات. وجـاءت أعلى عبارتين على النحو التالي: العبارة "r ا" (تتاولي لوجبـة الإفطار قليلـة ممـا

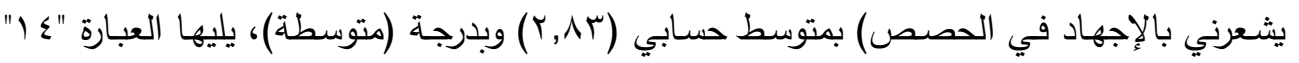
(أذهـب للفراش في وقت متأخر مدـا يشعرني بالنعـاس داخل الفصـل) بمتوسط حسـابي (Y,V0)

$$
\text { وبدرجة (متوسطة). }
$$

وجاءت أقل عبارتين على النحو التالي: العبارة "ه ا" (أعاني من مشكلة في السمع) بمتوسط

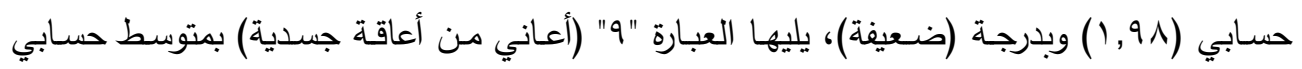

$$
\text { • (1, 1, ) وبدرجة (ضعيفة) }
$$

البعد الثالث: العوامل الأسرية 
جدول (1 (1): المتوسطات الحسابية والانحرافات المعيارية لأسباب التأخر الدراسي البعد الثالث: العوامل الأسرية

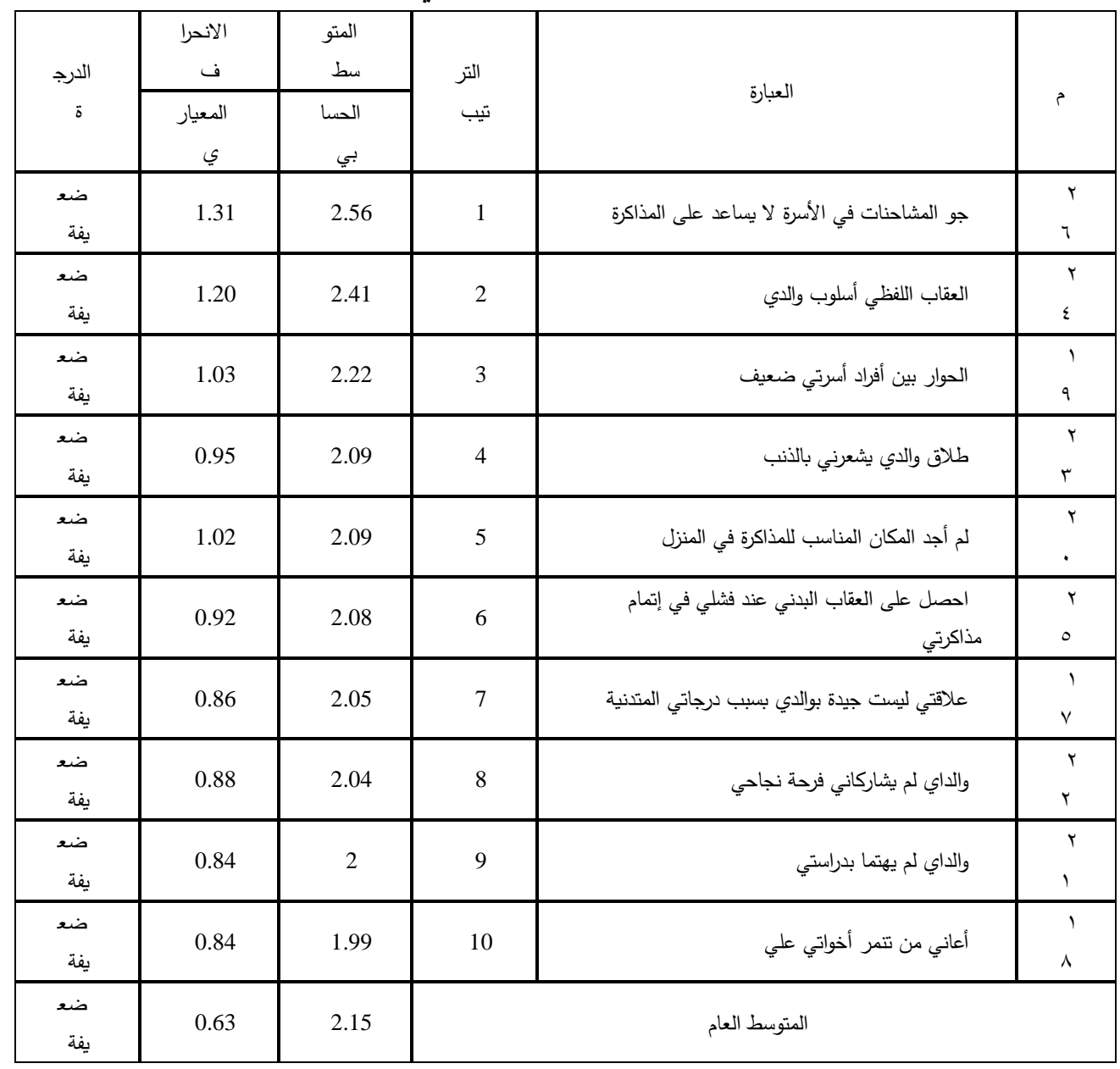

تثير نتائج جدول (1) أن المتوسط الحسابي العام لدرجة انتثار العوامل الأسرية كأحد

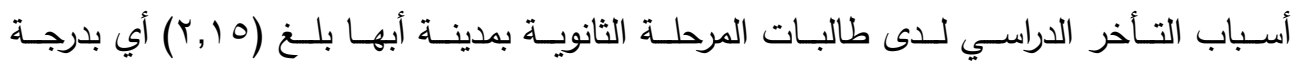

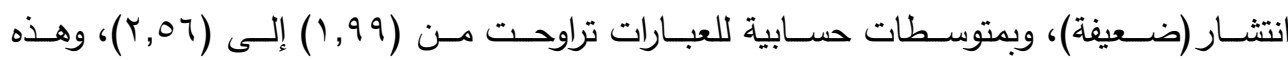
المتوسطات الحسابية تثير إلى درجة انتثار ضعيفة لجميع العبارات (• () عبارات. 
وجاءت أعلى عبارتين على النحو التالي: العبارة "جץ" (جو المشاحنات في الأسرة لا يساعد

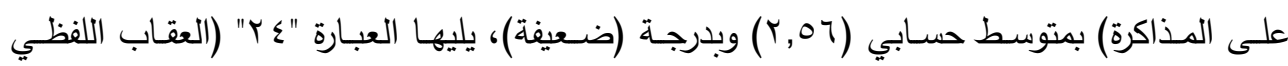

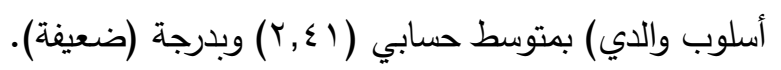

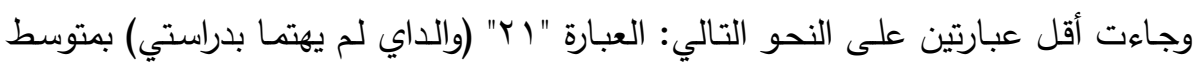

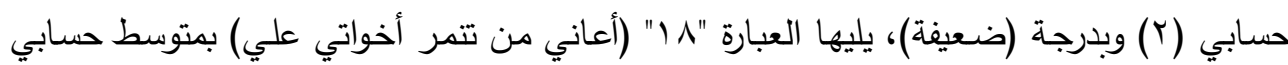

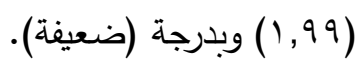

السؤال الثاني:

ما درجة تحقيق الذات لدى طالبات المرحلة الثانوية في مدينة أبها؟

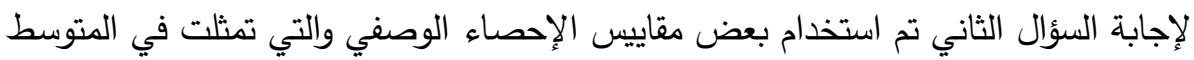

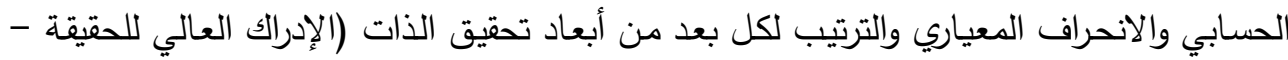

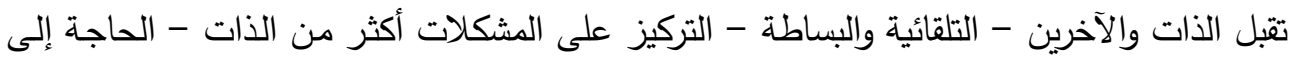

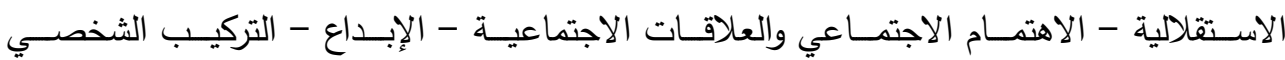

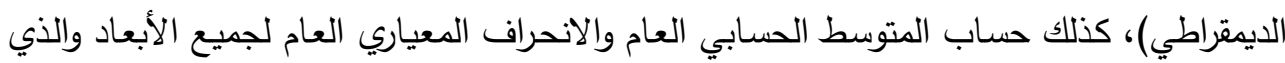
يمثل الدرجة الكلية لدقياس تحقيق الذات، وتم الحصول على النتائج التالية:

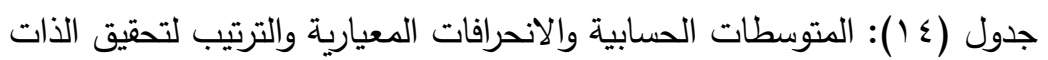

\begin{tabular}{|c|c|c|c|c|}
\hline تيب & التحقق & الالنحراف & الحسابي & البعد \\
\hline 。 & متوسطة & • & 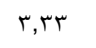 & الأول: الإدراك العالي للحقيقة \\
\hline 1 & 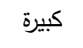 & ـ & $\varepsilon, 19$ & الثاني: تقبل الذات والآخرين \\
\hline r & 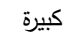 & . & $r, 90$ & الثالث: التلقائية والبساطة \\
\hline$\wedge$ & متوسطة & • & $r, \cdot r$ & الرابع: التركيز على المشكلات أكثر من \\
\hline$\varepsilon$ & كبيرة & $\cdot, \wedge$. & $r, v v$ & الخامس: الحاجة إلى الاستقلالية \\
\hline 1 & متوسطة & , VY & $r, r_{T}$ & السادس: الاهتمام الاجتماعي والعلاقات \\
\hline v & متوسطة & $\cdot, \lambda \vee$ & $r, \cdot r$ & السابع: الإبداع \\
\hline r & 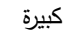 & $\cdot, \wedge \varepsilon$ & $\varepsilon, .7$ & الثامن: التركيب الثخصي الديمقراطي \\
\hline
\end{tabular}
لاى طالبات المرحلة الثانوية بمدينة أبها 


\begin{tabular}{|c|c|c|c|c|}
\hline- & كبيرة & . . OV & $r, 01$ & الدرجة الكلية \\
\hline
\end{tabular}

يلاحظ مـن جدول (乏 ) أن المتوسط الحسـي العـام لدرجـة تحقيق الذات لدى طالبـات

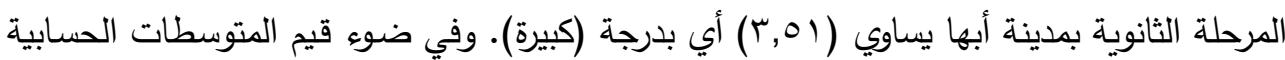
لأبعاد تحقيق الذات أمكن ترتيبها على النحو التالي: تقبل الذات والآخرين في الترتيب الأول بمتوسط باته

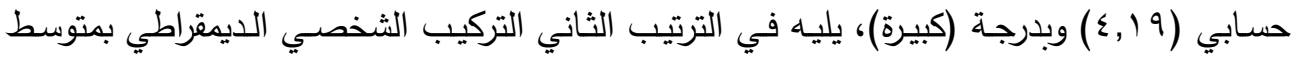

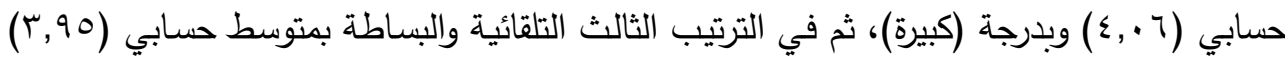

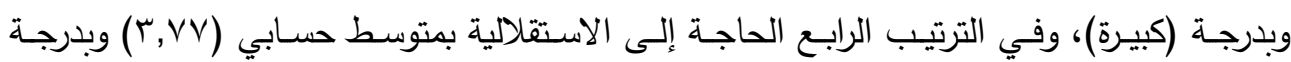

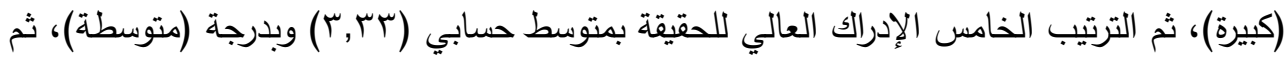

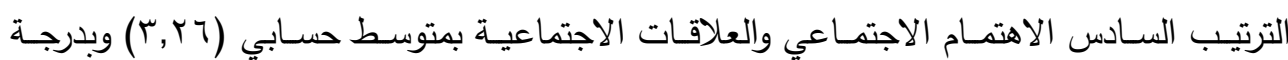

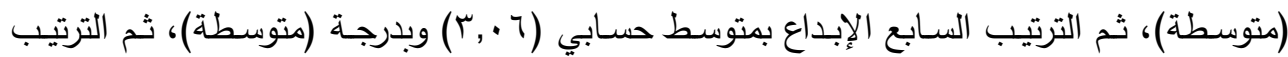

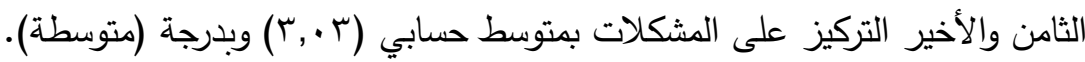
وفيما يلي وصفا لاستجابات عينة الدراسة على عبارات كل بعد من أبعاد تحقيق الذات: البعد الأول: الإدراك العالي للحقيقة جدول (0): المتوسطات الحسابية والانحرافات المعيارية لتحقيق الذات البعد الأول: الإدراك

\begin{tabular}{|c|c|c|c|c|c|}
\hline \multirow{2}{*}{ 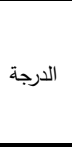 } & الانحرا & س المتو & التز & \multirow{2}{*}{ 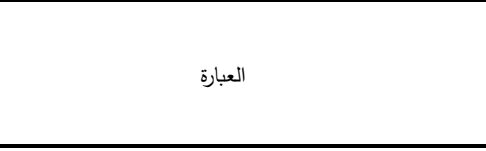 } & \multirow{2}{*}{ ? } \\
\hline & الميا & 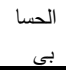 & تيب & & \\
\hline كبيرة & 0.82 & 4.25 & 1 & أشعر بأني على خلق ومهذبة. & r \\
\hline جبيرة & 0.87 & 4.23 & 2 & أشعر بالسعادة لسعادة الآخرين & 1 \\
\hline 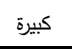 & 0.94 & 3.5 & 3 & تعجبني طريقتي الخاصة في عمل الأشياء & 9 \\
\hline 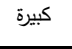 & 1.17 & 3.48 & 4 & شخصيتي قوية بين زميلاتي & $\wedge$ \\
\hline كبيرة & 1.24 & 3.46 & 5 & أعتبر نغسي مميزه بين زميلاتي وأقراني في معرفتي لما أريد. & r \\
\hline كبيرة & 1.26 & 3.44 & 6 & الآخربن وجهة نظري لموضوع ما بغض النظر عن وجهة نظر & v \\
\hline 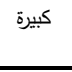 & 1.12 & 3.43 & 7 & أنا مستقلة فيأرائي & $\begin{array}{c}1 \\
r \\
\end{array}$ \\
\hline متوسط & 1.17 & 3.27 & 8 & أستطيع أن أواجه المواقف غير المألوفة بكفاءة & 1 \\
\hline متوسط & 1.13 & 3.24 & 9 & استخدم أساليب جديدة لحل المشكلات & ' \\
\hline متوسط & 1.22 & 3.18 & 10 & أتقبل الانتقادات البناءة من الآخرين & 。 \\
\hline
\end{tabular}




\begin{tabular}{|c|c|c|c|c|c|}
\hline فة ضعي & 1.37 & 2.29 & 11 & أقول ما أريد دون تحفظ. & 1 \\
\hline فة ضعد & 1.25 & 2.24 & 12 & أترفع عن هفوات الآخرين تجاهي & $\varepsilon$ \\
\hline متوسط & 0.64 & 3.33 & & المتوس & \\
\hline
\end{tabular}

تشير نتائج جدول 1) () أن المتوسط الحسابي العام لدرجة الإدراك العالي للحقيقة كأحد أبعاد

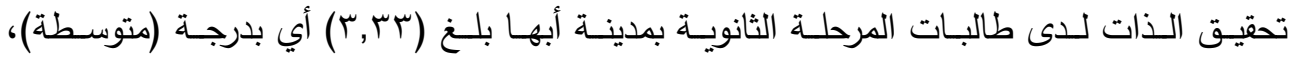

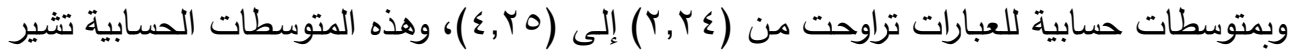

إلى درجة كبيرة جدا (r) عبارة، كبيرة (0) عبارات، متوسطة (r) عبارات، ضعيفة (r) عبارة.

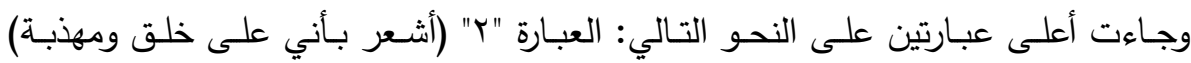

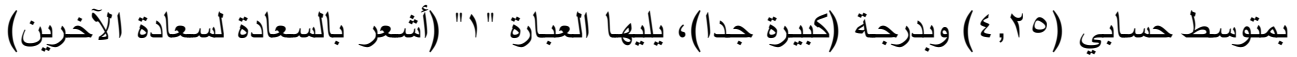

$$
\text { بمتوسط حسابي (س, § ) وبدرجة (كبيرة جدا). }
$$

وجاءت أقل عبارتين على النحو التالي: العبارة "ه" (أقول مـا أريد دون تحفظ) بمتوسط

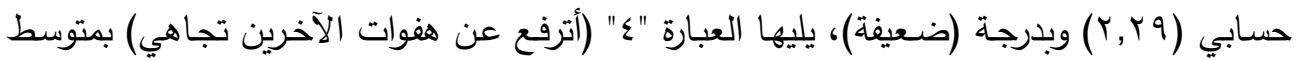
حسابي ( (Y,Y) وبدرجة (ضعيفة). البعد الثاني: تقبل الذات والآخرين جدول (7 (1): المتوسطات الحسابية والانحرافات المعيارية لتحقيق الذات البعد الثاني: تتبل

\begin{tabular}{|c|c|c|c|c|c|}
\hline \multirow{2}{*}{ 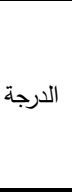 } & الانحرا & سط - المتو & 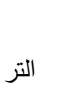 & \multirow{2}{*}{ 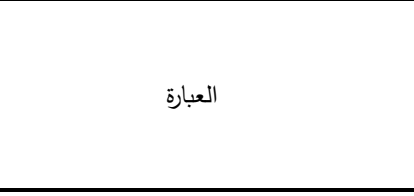 } & \multirow{2}{*}{ s } \\
\hline & المعيار & 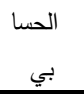 & تيب & & \\
\hline جبيرة & 0.76 & 4.53 & 1 & أشعر بالراحة عند تقديم المساعدة للآخرين & 1 \\
\hline جبيرة & 0.83 & 4.43 & 2 & أتعامل مع الآخرين بمودة & v \\
\hline جبيرة & 0.85 & 4.42 & 3 & الأعمال التطوعية تثعرني بالسعادة & ' \\
\hline كبيرة & 0.99 & 4.2 & 4 & بها أشعر بالرضا عن مستوى الأعمال التي أقوم & 1 \\
\hline كبيرة كبرة & 1.04 & 4.19 & 5 & أجتهد في محاولة إسعاد الآخرين & । \\
\hline كبيرة & 1.15 & 3.9 & 6 & أشعر بالمتعة والسعادة أثناء تأدية عملي & r \\
\hline
\end{tabular}




\begin{tabular}{|c|c|c|c|c|c|}
\hline كبيرة & 1.23 & 3.64 & 7 & لذاتي أتقبل انتقاد الآخرين لأعمالي دون تجريح & । \\
\hline كبيرة & 0.64 & 4.19 & & المتوسط العام & \\
\hline
\end{tabular}

تثير نتائج جدول (T (1) أن المتوسط الحسابي العام لدرجة تقبل الذات والآخرين كأحد أبعاد

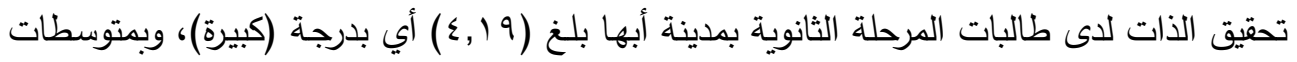

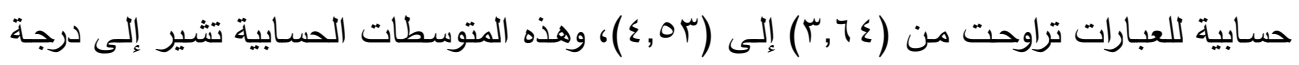
كبيرة جدا (r) عبارات، كبيرة (ع) عبارات.

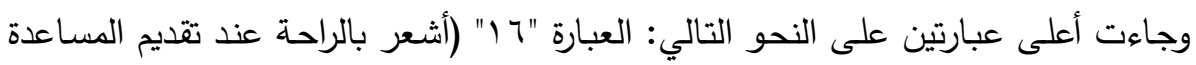

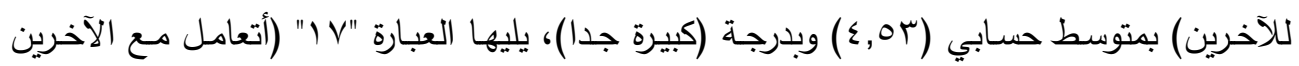
بمودة) بمتوسط حسابي (r \&, §) وبدرجة (كبيرة جدا).

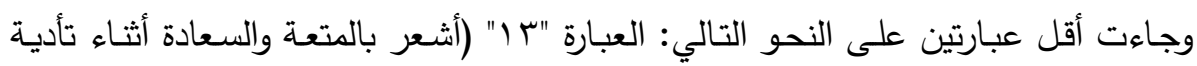

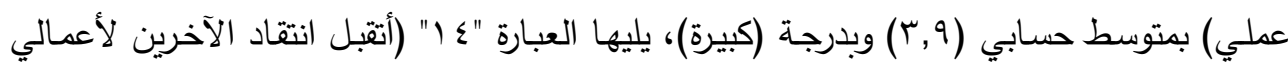
دون تجريح لذاتي) بمتوسط حسابي (ع ب, ب) وبدرجة (كبيرة). السؤال الثالث:

هل توجد علاقة ارتباطية ذات دلالة إحصائية بين أسباب التأخر الدراسي وتحقيق الذات

لطالبات المرحلة الثانوية في مدينة أبها؟ لإجابـة السؤال الثالث تم استخدام معامل ارتباط بيرسون لحسبـاب العلاقـة الارتباطية بين درجات أسباب التأخر الدراسي (العوامل النفسية -العوامل الجسدية والصحية - العوامل الأسرية العوامل العقلية - العوامل التعليمية والتعلمية)ودرجات تحقيق الذات (الإدراك العالي للحقيقة - تقبل

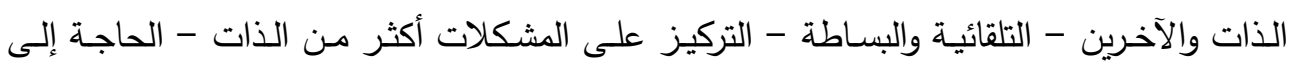

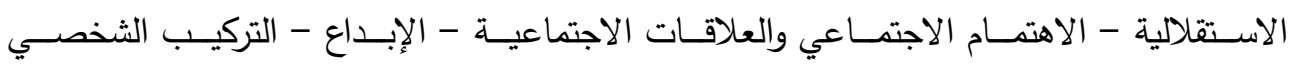
الديمقراطي) لدى طالبات المرحلة الثانوية بدينة أبها، وكانت النتائج كالتالي: 
جدول (rr): معاملات الارتباط بين درجات أسباب التأخر الدراسي ودرجات تحقيق الذات

\begin{tabular}{|c|c|c|c|c|c|c|}
\hline الكلية & التعلعيمية & العقلية & الأسرية & والصحدية & النفسية & \\
\hline $\begin{array}{l}- \\
., \text { orv }\end{array}$ & $\cdot, 0 \leqslant 0-$ & $\begin{array}{l}- \\
., \& 1 \leqslant\end{array}$ & - & $\begin{array}{l}- \\
., \Delta \wedge r\end{array}$ & $\begin{array}{l}- \\
., 0 \mathrm{PY}\end{array}$ & لالإدراك العالي \\
\hline $\begin{array}{l}- \\
., 001\end{array}$ & $\cdot, 0 Y \mu-$ & $\begin{array}{l}- \\
., 09 \mathrm{~V}\end{array}$ & - & $\begin{array}{l}- \\
., 0+9\end{array}$ & $\begin{array}{l}- \\
., O \wedge r\end{array}$ & تقبل الأات \\
\hline $\begin{array}{l}- \\
., 091\end{array}$ & $\cdot,, \leqslant \wedge \wedge-$ & $\begin{array}{l}- \\
., T r V\end{array}$ & $\cdot, 00 \leqslant-$ & $\begin{array}{l}-\overline{1} \\
.,+1 \wedge\end{array}$ & $\overline{-}$. & والتبساطة \\
\hline$\overline{-}$ & $\cdot,\{\vee \vee-$ & $\begin{array}{l}- \\
.04 r\end{array}$ & ., YYV- & $\begin{array}{l}- \\
., 09 \mathrm{~V}\end{array}$ & $\begin{array}{l}- \\
., \varepsilon 1 \leqslant\end{array}$ & المشكلات أكثر الذر \\
\hline $\begin{array}{l}- \\
., 4 V_{1}\end{array}$ & ., ०४४- & $\begin{array}{l}- \\
.,\{V V\end{array}$ & $\cdot, \leqslant \wedge \wedge-$ & $\begin{array}{l}- \\
., \text { ORT }\end{array}$ & $\begin{array}{l}- \\
., 0 \leq 0\end{array}$ & الاستقلال إلى \\
\hline $\begin{array}{l}- \\
., 0 \leqslant \leqslant\end{array}$ & $\cdot,+, \vee 1-$ & $\bar{r}$ &., $091-$ & $\begin{array}{l}- \\
., 001\end{array}$ & $\begin{array}{l}- \\
., \text { OUV }\end{array}$ & الاجاجتماعيام \\
\hline $\begin{array}{l} \\
., T H\end{array}$ & - & $\begin{array}{l}- \\
., 0 \vee \leqslant \varepsilon\end{array}$ & .,oro- & $\begin{array}{l}- \\
., \text { OHY }\end{array}$ & $\begin{array}{l}- \\
-,, \varepsilon \vee r\end{array}$ & الإِداع \\
\hline $\begin{array}{l}- \\
., i r V\end{array}$ & $\cdot,, \leq 9 \leq-$ & $\begin{array}{l}- \\
., 0 \wedge .\end{array}$ & $\cdot, 010-$ & $\begin{array}{l}- \\
.,\{\wedge 9 \\
\end{array}$ & $\begin{array}{l}- \\
., \& \wedge 9 \\
\end{array}$ & الثخصريب التركيب \\
\hline $\begin{array}{l}- \\
., \mathrm{iTV}\end{array}$ & . & $-\bar{c}$ & , ror- & $\begin{array}{l}- \\
., 4 \times 4\end{array}$ & $-\overline{1}$ & الدرجة الكلية \\
\hline
\end{tabular}

تشير نتائج جدول (Yr) إلى وجود علاقة ارتباطيه سالبة ذات دلالة إحصائية عند مستوى

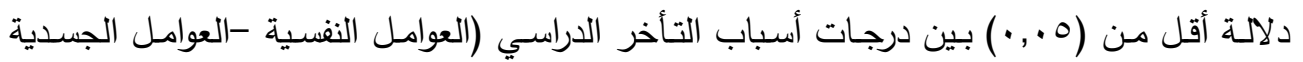
والصحية - العوامل الأسرية - العوامل العقلية - العوامل التعليمية والتعلمية)ودرجات تحقيق الذات دات التابل

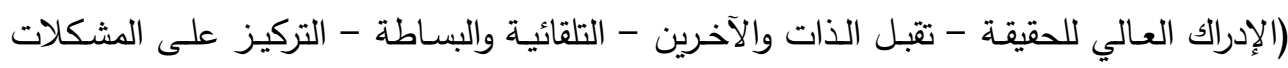

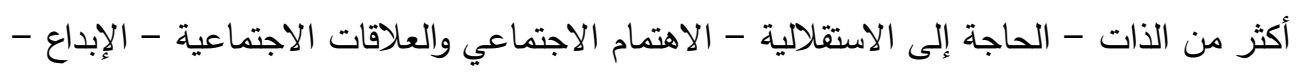

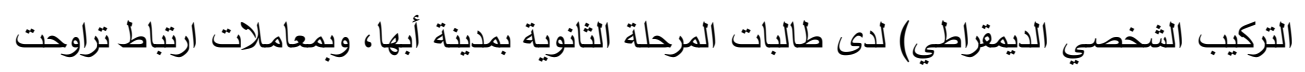

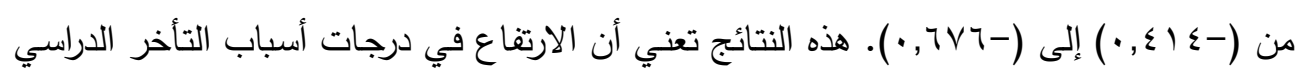
يصاحبها انخفاض في درجات تحقيق الذات لدى طالبات المرحلة الثانوية بمدينة أبها. السؤال السادس 
هل يمكن التتبؤ بتحقيق الذات من خلال أسباب التأخر الدراسي لطالبات المرحلة الثانوية في

$$
\text { مدينة أبها؟ }
$$

لإجابة السؤال السادس، تم استخدام أسلوب الانحدار المتعدد، حيث استخدم أسباب التأخر

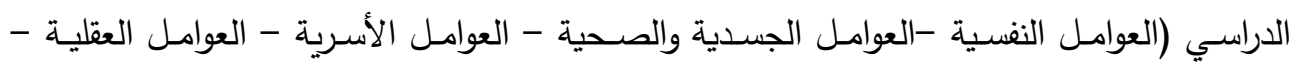
العوامل التعليمية والتعلمية) كمتغيرات مستقلة، وتحقيق الذات كمتغير تابع وتم دراسة إمكانية التتبؤ

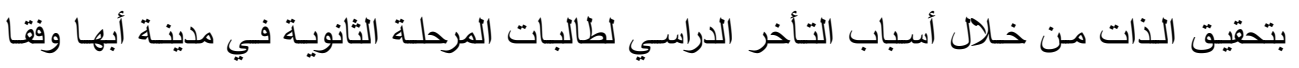
للخطوات التالية:

أولا: معرفة هل يوجد تأثير لأسباب التأخر الدراسي على تحقيق الذات

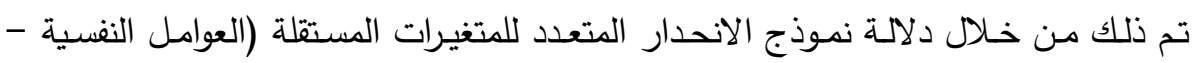
العوامل الجسدية والصحية - العوامل الأسرية - العوامل العقلية - العوامل التعليمية والتعلمية) على الإنى المتغير التابع (تحقيق الذات) وكانت النتائج كالتالي:

جدول (rr): دلالة نموذج الانحدار المتعدد لمعرفة تأثير أسباب التأخر الدراسي على تحقيق الذات

\begin{tabular}{|c|c|c|c|c|c|c|}
\hline 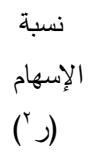 & الإحصائية & فيمة & المربعات & الحرية & المربعات & الاختلاف \\
\hline \multirow{3}{*}{0.23} & \multirow{3}{*}{0.00} & \multirow{3}{*}{$\begin{array}{c}26.5 \\
3\end{array}$} & 6.72 & 5 & 33.59 & الانحدار \\
\hline & & & 0.25 & 444 & 112.42 & المتبقي \\
\hline & & & & 449 & 146.01 & الكلي \\
\hline
\end{tabular}

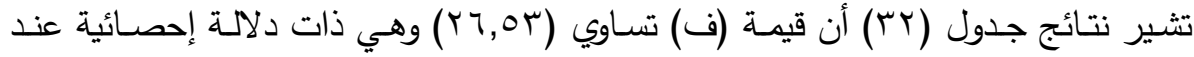
مستوى دلالة أقل من (0. . •)، وهذا يعني وجود تأثير كبير وذو دلالة إحصائية للمتغيرات المستقلة (أسباب التأخر الدراسي) على المتغير التابع (تحقيق الذات).

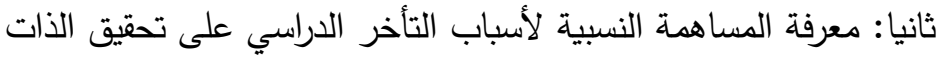

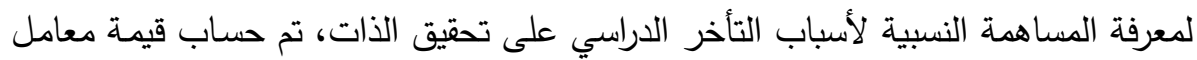
التقدير (رّ) وهو يمثل حجم الأثر أو ما يسمى بمقدار الإسهام النسبي للمتغيرات المستقلة (أسباب

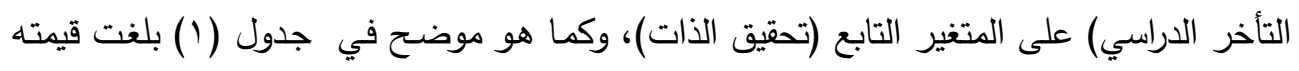

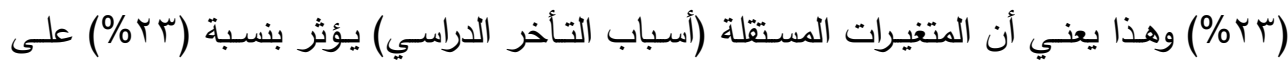




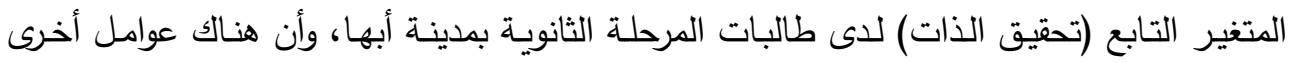
بخلاف (أسباب التأخر الدراسي) لها تأثير أيضـا على (تحقيق الذات) لم تتتاولها الدراسـة الحالية

وتصل نسبتها (\%VV).

ثالثا: الحصول على معادلة التتبؤ بتحقيق الذات من خلال التأخر الدراسي

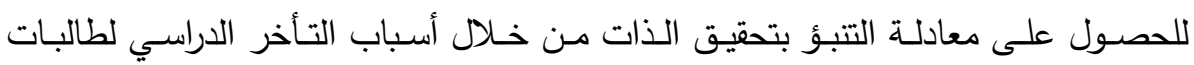

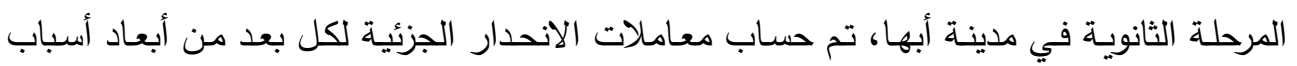
التأخر الدراسي وكانت النتائج كالتالي: جدول (Tr): معاملات الانحدار الجزئية للتنبؤ بتحقيق الذات من خلال أسباب التأخر الدراسي

\begin{tabular}{|c|c|c|c|c|}
\hline الإحصائية & الانحدار & نموذج الانحدار & الت التغير & المستغل \\
\hline$\cdot, \cdot$ & $r, 1 \cdot \lambda$ & الثابت (متغيرات أخرى) & \multirow{6}{*}{ الذات } & \multirow{6}{*}{ ألداسب التأخر } \\
\hline$\therefore, \cdot$ &.,- 119 & العوامل النغسية & & \\
\hline .,.r & $-\cdot, 1, r$ & العوامل الجسدية & & \\
\hline$\cdot, \cdot$ &.,$- 1+4$ & العوامل الأسرية & & \\
\hline$\cdot, \cdot$ &.,$- 11 \leqslant$ & العوامل العقلية & & \\
\hline$\cdot,$. & $-0,1 T T$ & العوامل التعليمية & & \\
\hline
\end{tabular}

في ضوء نتائج جدول (rr) يلاحظ أن معاملات الانحدار لجميع أسباب التأخر الدراسي

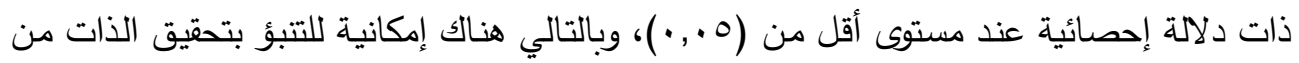
خلال أسباب التأخر الدراسي لطالبات المرحلة الثانوية في مدينة أبها، وفقا لمعادلة التتبؤ التالية:

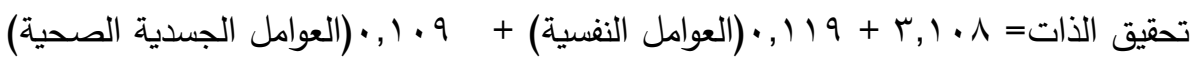

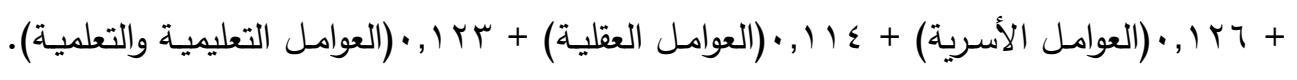
ويمكن استخدام تلك المعادلة من قبل إدارة المدرسة للتتبؤ بتحقيق الذات من خلال أسباب التأخر الترابه الدراسي.

\section{الفصل الخامس: نتائج الاراسة وتوصياتها ومقترحاتها}

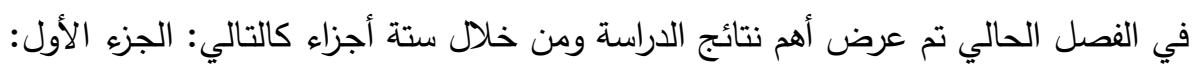
أهم نتائج درجة أسباب التأخر الدراسي لدى طالبات المرحلة الثانوية بمدينة أبها، الجزء الثاني: أهم الثماء 
نتائج درجة تحقيق الذات لدى طالبات المرحلة الثانوية بمدينة أبها، الجزء الثالث: أهم نتائج العلاقة

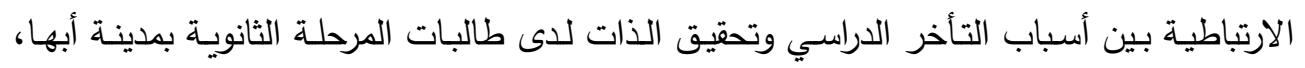

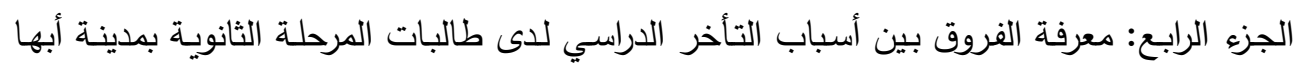

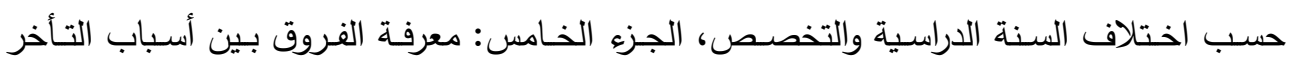

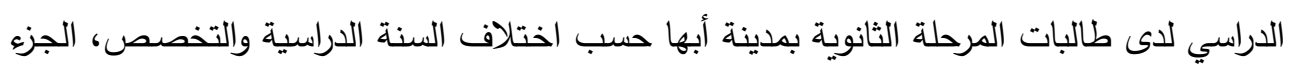

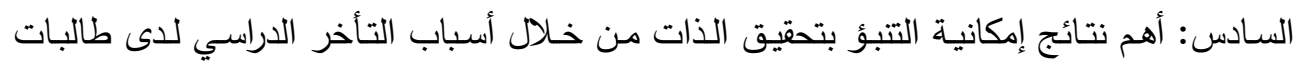

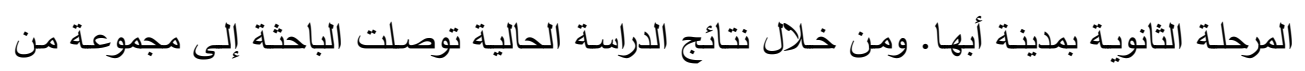

$$
\begin{aligned}
& \text { التوصيات، وأخيرا مجموعة من الدراسات والبحوث المقترحة. } \\
& \text { الجزء الأول: أهم نتائج أسباب التأخر الدراسي لئي }
\end{aligned}
$$

• المتوسط الحسابي العام لدرجة انتشار أسباب التأخر الدراسي لأى طالبات الدات المرحلة

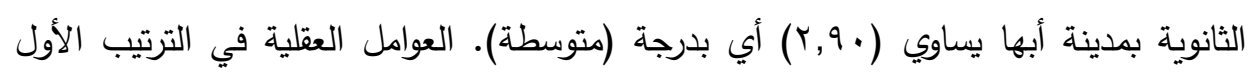

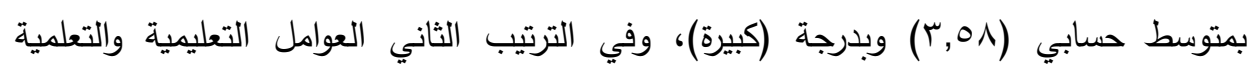

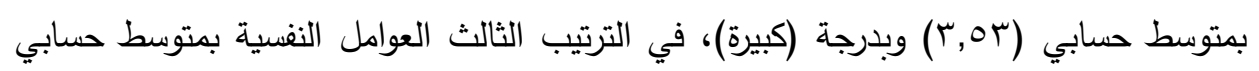

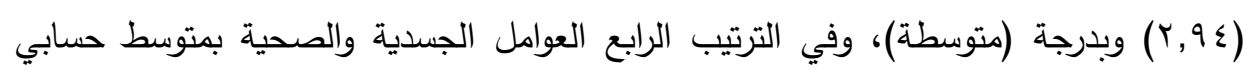

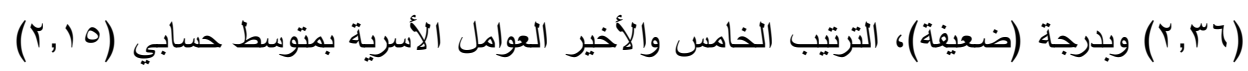

$$
\text { وبدرجة (ضعيفة). }
$$

• المتوسط الحسابي العام لدرجة تحقيق الذات لدى طالبات المرحلة الثانوية بمدينة أبها

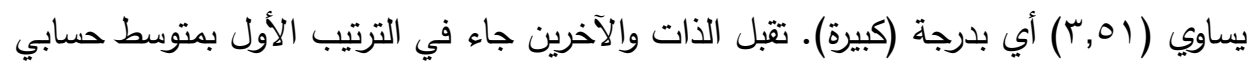

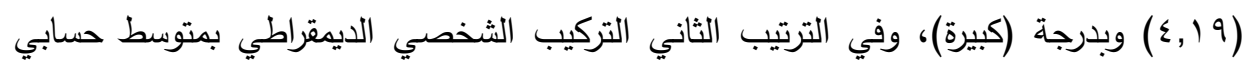

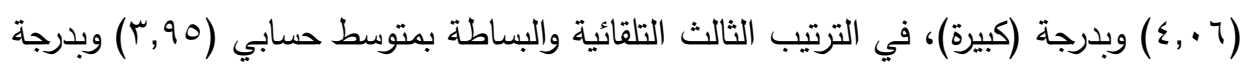

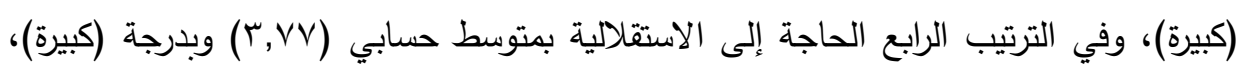

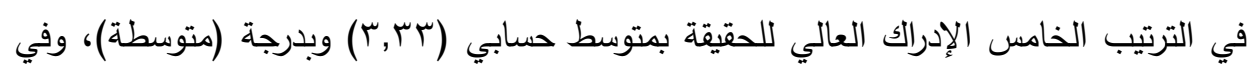

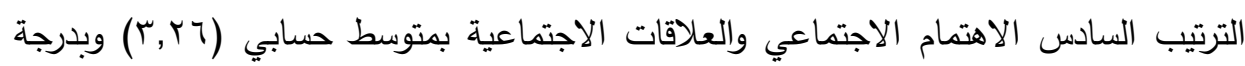

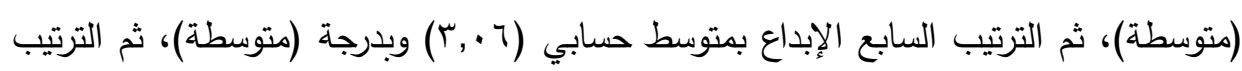

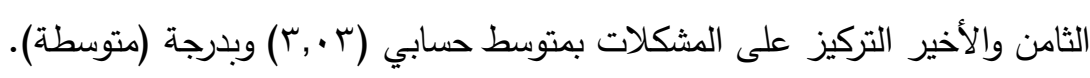


حيث إن التوصيات تتبثق من النتائج، لذا توصي الباحثة بما يلي:

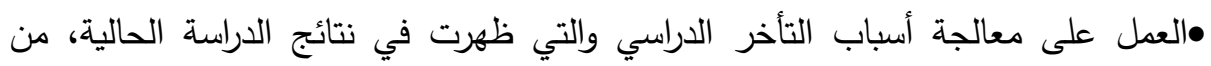
خلال التوعية والبرامج الإرشادية والتعاون بين المدرسة والأسرة.

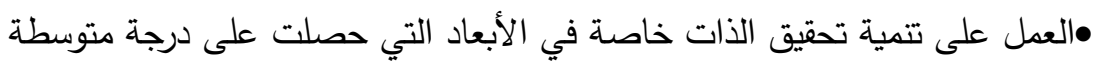

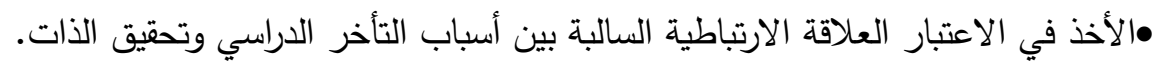

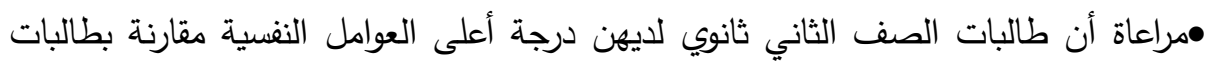

$$
\text { الصف الأول والثالث. }
$$

•إجراء دراسة تطبق على مناطق أخرى بالمملكة. •إجراء دراسة تطبق على الذكور

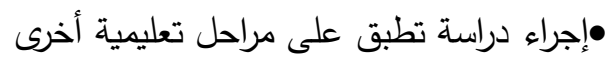
•إجراء دراسة تتناول علاقة أسباب التأخر الدراسي بمتغيرات أخرى غير أخرى تحقيق الذات مثل: مستوى الطموح، الدافعية للإنجاز ، قلق المستقبل.

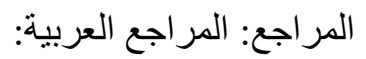

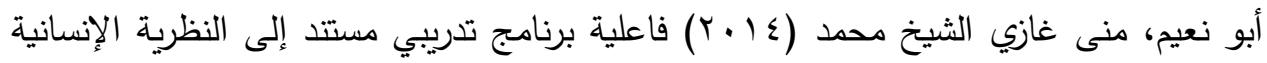

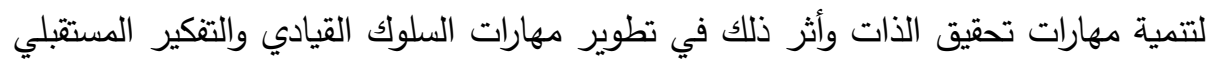
لاى طالبات الصف السادس الأساسي، عمان رسالة دكتوراه، الجامعة الأردنية، كلية الدراسات العلياء الأردن

ابراهيم، محمد عزيز وحسب الله محمد الحليم (ץ . . ץ). التفاعل الصفي، مفهومه. وتحليلهمهاراته، (ط ())، القاهرة، عالم الكتب.

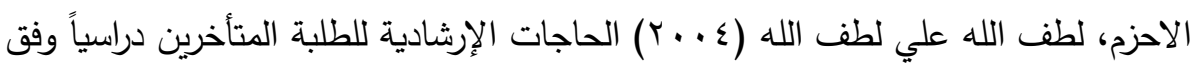
سماتهم الثخصية، رسالة ماجستير، كلية التربية، جامعة صنعاء، اليمن.

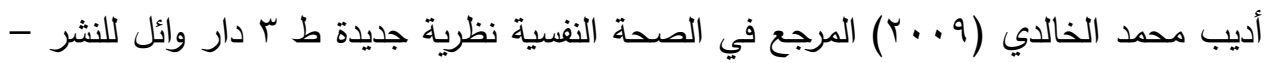
عمان - الأردن 
اسماعيل ابراهيم، (9 . . ؟). الاتجاهات المعاصرة في اعداد برامج علاجية لمشكلة التأخر الدراسي

$$
\text { (الانترنيت). }
$$

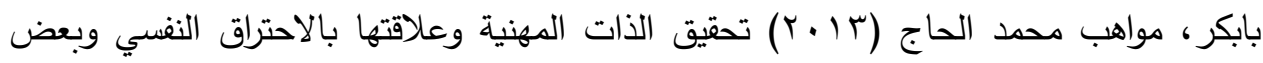

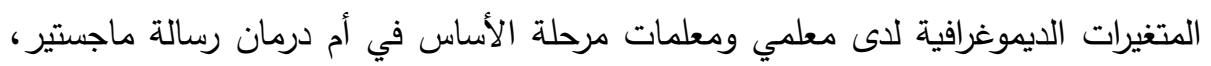

$$
\text { جامعة أم درمان الإسلامية، كلية التربية السودان. }
$$

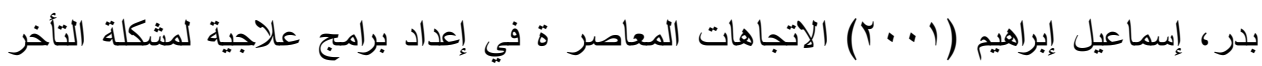

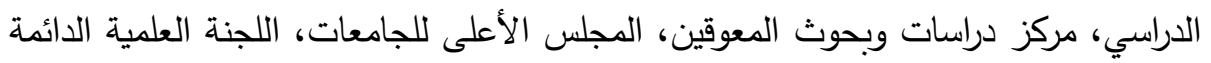

$$
\text { للتربية وعلم النفس. }
$$

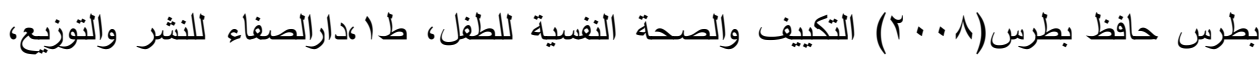

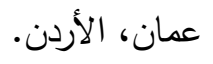

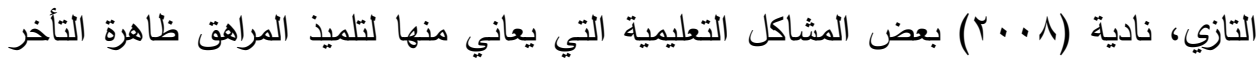

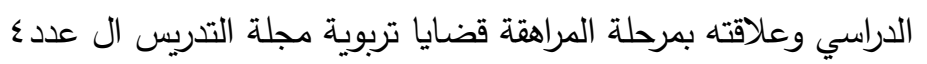

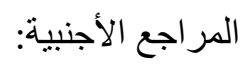

Bahram ,Somayeh $(r \ldots 0)$ Effectiveness of life skills training on increasing self-esteem of high, school students- Social and Behavioral Sciences , vol. I rov - Iror, (rr)

Carlson, N. R. (1992). Memory. Psychology: the science of behavior (Canadian ed., p. 461). Scarborough, Ont.: Allyn and Bacon Canada.

Chubbuck, F. (2008). A study On the Correlation between Self Efficacy \& Foreign Language Learning Anxiety, Journal of Theory \& Practice in Education, 4 (1), .148-158.

Doyle،James، 1976،self-Actuallization Neuroticism and extra version revised psychology ictal repots vol (39).

Engler, B. (2006). Personality theories: an introduction (8th ed.). Boston, MA: Houghton Mifflin. 